\title{
Endogenous Labor Market Participation and the Business Cycle
}

\author{
Christian Haefke \\ Instituto de Análisis Económico, CSIC \\ christian.haefke@upf.edu
}

\author{
Michael Reiter \\ Universitat Pompeu Fabra \\ michael.reiter@upf.edu
}

March 2006

\begin{abstract}
Existing models of equilibrium unemployment with endogenous labor market participation are complex, generate procyclical unemployment rates and cannot match unemployment variability relative to GDP. We embed endogenous participation in a simple, tractable job market matching model, show analytically how variations in the participation rate are driven by the crosssectional density of home productivity near the participation threshold, and how this density translates into an extensive-margin labor supply elasticity.

A calibration of the model to macro data not only matches employment and participation variabilities but also generates strongly countercyclical unemployment rates. With some wage rigidity the model also matches unemployment variations well. Furthermore, the labor supply elasticity implied by our calibration is consistent with microeconometric evidence for the US.
\end{abstract}

Key Words: Matching Models, Labor Market Participation, Labor Supply Elasticity, Time Aggregation.

JEL Classification: E24, E32, J21, J64.

We are grateful to Wouter den Haan for a very helpful discussion of an early draft of this paper. We thank Albert Marcet, Jaume Ventura, Étienne Wasmer, and seminar participants from UPF, IAE, and IHS Vienna for useful comments. Robert Shimer, Elisa Faraglia, and Hoyt Bleakley provided the raw CPS data. All remaining errors are ours. Haefke acknowledges financial support from Spanish ministry grants SEJ2004-03149 and SEJ2004-03619. Reiter acknowledges financial support from Spanish ministry grants SEJ2004-03619 and SEC2002-01601. 


\section{Introduction}

It is now widely recognized that the labor market participation rate is an important determinant of aggregate output dynamics in the long run (Ngai and Pissarides, 2006). A large part of the difference in GDP per capita between the US and Europe can be explained by the higher participation rate in the US (Prescott, 2004). What has not been clear so far is whether short-run fluctuations of the participation rate play a significant role in modeling the business cycle. On the one hand, Shimer (2005b) documents that flows into and out of the labor force are crucial to explain employment and unemployment variability, on the other hand the fluctuations in the participation rate over the cycle have not been very strong over the last decades. Moreover, existing models that attempt to explain the cyclical behavior of the participation rate generate grossly counterfactual implications for key labor market statistics such as a positive correlation of unemployment and GDP. This has lead to the conclusion that standard theories of search may be incompatible with endogenous search intensity (Shimer, 2004) or endogenous participation decisions (Veracierto, 2004).

In this paper, however, we show that a standard model of labor search and endogenous labor market participation is successful in explaining the dynamics of labor market aggregates over the business cycle. In particular, our model generates a strong negative correlation between unemployment and GDP. We find that endogenous participation helps in explaining the variability of employment over the cycle. It gives a greater magnification of technology shocks than the standard matching model. A flexible wage version of the model shares the well known shortcoming of the matching model that it underpredicts the observed unemployment fluctuations. We therefore consider a simple form of wage rigidity as suggested by Shimer (2005a). This version of the model jointly explains the variability of employment, participation, and unemployment.

We carefully investigate which features of our model are necessary to explain the countercyclical response of unemployment. The intuition behind the procyclical unemployment rate in previous papers (Faraglia, 2003; Shimer, 2004; Tripier, 2002; Veracierto, 2004) is that a large number of people join the labor force in booms when expected wages are high. Matching, however, takes time and so the unemployment rate initially increases in booms, until the new entrants are absorbed into employment. ${ }^{3}$ The strength of this effect depends crucially on the mass of workers

\footnotetext{
${ }^{3}$ This argument is also present in the popular press (Reuters, 2004) and in speeches by Fed Governor Kohn (2004).
} 
that are close to the participation margin. We calibrate this density using information on the cross-sectional distribution of market wages. It turns out that with this calibration, the model explains the cyclical variability of participation, and in addition generates an aggregate labor supply elasticity that is consistent with recent microeconometric evidence.

We are not the first to model participation decisions in a job matching framework. Recently, Pries and Rogerson (2004) have emphasized the heterogeneity of expected durations in participation spells and implications for cross-country differences. Kim (2003) and Garibaldi and Wasmer (2005) have studied the effects of labor market policies in matching models with endogenous participation. They consider only steady states, not fluctuations. The model setup in Garibaldi and Wasmer (2005) is particularly similar to ours in many respects. Our finding that endogenous participation is successful in modeling labor market fluctuations supports those models and strengthens their findings.

The outline of the paper is as follows. Section 2 presents the theoretical model and some analytical results. Section 3 discusses the data and calibration. Sections 4 and 5 provide numerical results for the calibrated model and Section 6 concludes. Proofs are in Appendix A.

\section{Model}

The model is in the spirit of the simplest model of equilibrium unemployment (e.g. Pissarides 2000, chapter 1). We shall introduce the participation decision in a very tractable way, such that we can handle both idiosyncratic and aggregate shocks easily. First we discuss the household decision problem and subsequently describe the formation of employment relationships and the wage determination. We characterize the steady state equilibrium and illustrate the effect of participation using comparative statics. In this context two important simplifying assumptions are presented, which will help to limit the degree of heterogeneity in the labor market and make more analytical results available. Finally we analyze the model dynamics in the presence of aggregate shocks with and without the simplifying assumptions.

\subsection{Basic setup}

\subsubsection{Households}

The economy is populated by a constant mass of ex ante identical one-person households, which we call workers. The situation of each worker at time $t$ is characterized 
by two idiosyncratic state variables, her employment status $s(t)$ (either employed, $s(t)=e$, or not employed, $s(t)=n)$, and her current level of home productivity $h(t)$.

Those who are not employed can choose to actively search for a job, and thus participate in the labor market, or not. This is the only decision that the agents have to make. Those who decide not to participate but rather stay at home are called nonparticipants, or out of the labor force. They engage in home production which yields the utility flow $h(t)$. We think of this utility as all kinds of returns to being at home, from taking care of your children or growing vegetables in your backyard to moonlighting. Obviously, home productivity varies over time due to life cycle and other reasons, and we allow for this by assuming that $h(t)$ is redrawn from a distribution $F(h)$ with constant exogenous Poisson arrival rate $\eta$. Changing idiosyncratic home productivity over time implies that flows into and out of the labor force occur even in the absence of aggregate shocks. For example, a high enough draw of $h$ can induce unemployed agents to leave the labor force. The steady state analysis of participation by Pissarides (2000, chapter 7) abstracts from changes in idiosyncratic home productivity, which limits its applicability to longrun considerations.

Nonemployed agents who actively search for a job are called unemployed and by definition participate in the labor market. They receive the flow utility $b(h)$, which includes unemployment benefits and some level of home production, net of search costs, which in general will depend on the worker's home productivity $h$. We assume

$$
0 \leq b^{\prime}(h) \leq 1
$$

A searcher's probability $\lambda$ of finding a job depends only on the aggregate state of nature. The worker cannot increase this probability. Those who are employed do not enjoy any home production, but they earn a wage $w$. The wage depends on the productivity of the match, and in general also on home productivity $h$. To obtain a very simple and tractable model, we will later state assumptions that guarantee that the wage is the same for all workers.

We assume that match output is equal to aggregate productivity $z$. Thus all workers have the same market productivity and differ only in home productivity. In reality, it is clear that both types of productivity vary between households and over time. What determines the participation decision is mainly the difference between market and home productivity. For simplicity, however, all models that we know of set either market or home productivity as constant across agents. For example, Chang and Kim (2003a) and Pries and Rogerson (2004) let the market productivity vary, while in Pissarides (2000, Chapter 7) or Garibaldi and Wasmer 
(2005) it is the home productivity that varies. In this respect, we follow the second approach, because it turns out that a model with constant market and variable home productivity is much easier to handle, as will become clear in Section 2.5.

Notice also that there is no cost of switching between unemployment and nonparticipation, and a household's decision to participate is therefore independent of whether the household participated last period or not. In this sense, nonparticipation is not a third (predetermined) labor market state, but only a decision variable of the household. ${ }^{4}$

\subsubsection{Job Creation and Wage Determination}

All filled jobs at time $t$ produce output at the flow rate $z(t)$, because the market productivity is the same across workers. Job separations are purely exogenous and occur with constant flow probability $\chi$. We make this assumption not only for simplicity. Indeed, it is straightforward to incorporate endogenous separations. The point of this assumption is to highlight that the negative correlation between GDP and unemployment in the model is not caused by an anticyclical separation rate, but by the dynamics of firms' hirings. Furthermore, it has recently been argued (Shimer, 2005b) from an empirical standpoint that the separation rate is roughly constant over the business cycle.

To form new employment relationships, workers must search and firms must post vacancies. In line with the literature, we assume that the total number of new matches $M$ is produced by a Cobb-Douglas matching function

$$
M=\mu U^{\vartheta} V^{1-\vartheta}
$$

where $U$ is the size of the unemployment pool (the non-employed who search), $V$ is the total number of vacancies, $\mu$ is a scaling parameter and $\vartheta$ is the matching elasticity. Defining aggregate labor market tightness $\theta \equiv V / U$, we obtain the matching probabilities of the firm and the worker $(\lambda)$ as

$$
\begin{aligned}
& \frac{M}{V}=q(\theta) \\
& \frac{M}{U}=\theta q(\theta) \equiv \lambda
\end{aligned}
$$

where

$$
q(\theta) \equiv \mu \theta^{-\vartheta}
$$

\footnotetext{
${ }^{4}$ We have been experimenting with an extended version of the model to allow for a fixed cost of entering the labor market. It turned out that this has very little effect on our main results for reasonable values of the fixed cost, and so these experiments are not reported here.
} 
Wages are determined by generalized Nash bargaining ${ }^{5}$. The corresponding first order condition is

$$
\frac{\alpha}{1-\alpha}=\frac{\Sigma_{i}^{W}(h)}{J_{i}(h)}
$$

where $\alpha$ is the bargaining weight of the worker, $\Sigma_{i}^{W}(h)$ is the surplus that a worker with home productivity $h$ gets from having a job when aggregate productivity is $z_{i}$, and $J_{i}(h)$ is the value that the firm has from having the job filled. Formulas for $\Sigma_{i}^{W}(h)$ and $J_{i}(h)$ will be derived below.

In order to post a vacancy, firms have to pay a hiring cost of $\phi$ per unit time. Free entry assures that expected values of a vacancy are zero. Therefore the expected surplus that a worker generates for the firm has to equal the expected hiring cost.

\subsubsection{Aggregate productivity}

The output of employment relationships at time $t$ is determined by the aggregate productivity parameter $z(t)$. It follows a finite-state continuous-time Markov process, taking values $z_{i}$ where $i=1, \ldots, N_{z}$. The Poisson rate at which the process switches from realization $z_{i}$ to $z_{j}$ is denoted by $p_{i, j}$. Since our model is in continuous time, $p_{i, j}$ is the rate at which the probability to be in state $z_{j}$ increases over time if we start from $z_{i}$. Therefore $p_{i, i}=-\sum_{j \neq i} p_{i, j}$.

\subsection{Important special cases}

In much of the following analysis we will consider two special cases that significantly simplify the model. Since none of these assumptions is obviously realistic, we will document carefully how the model solution changes when we relax these assumptions.

One important complication in the model is that the home productivity of a worker enters the outside option in the wage negotiation, such that workers with higher home productivity end up getting higher wages. To avoid this, we will often make the assumption that workers cannot realize their home productivity while engaged in search activities. Workers then only receive a constant utility flow $b_{0}$, which can be interpreted as unemployment benefits plus some minimum home productivity:

\footnotetext{
${ }^{5}$ We are aware that continuous Nash bargaining is blamed as the major culprit of the matching model's incapability to generate large unemployment fluctuations. It is trivial to substitute other wage determination mechanisms for Nash bargaining in this model, as we will illustrate in Section 2.6. However, it is instructive to start from the best understood case, which is still Nash bargaining.
} 
Assumption 1 (ConstB). The flow utility while unemployed is the same for all workers, $b(h) \equiv b_{0}$.

We will see in Section 2.3 that in the model without aggregate shocks, this assumption is sufficient to make all workers get the same wage. In the model with aggregate productivity shocks, we need an additional assumption that is introduced in Section 2.4.

To understand the next assumption, recall that we have assumed that a nonemployed worker redraws home productivity with flow probability $\eta$, while an employed worker redraws only at job separation, which happens with probability $\chi$. This introduces some unusual incentives. For example, when $\chi>\eta$, a nonemployed with low home productivity has an incentive to look for a job not just because she then collects a wage, but also because employment increases her chances for a new draw of home productivity. This is somewhat artificial; a more complicated model (Garibaldi and Wasmer, 2005) would separate these two events, and consider endogenous separation after the redraw of an employed worker. Rather than complicating the model, we simplify it by considering the special case where the two probabilities are equal.

Assumption 2 (EtaChi). The job separation rate equals the redraw probability, $\eta=\chi$.

We will show that relaxing this assumption does not change any qualitative conclusions.

\subsection{The model with constant aggregate labor productivity}

Before looking at the model with aggregate productivity shocks, it is worthwhile to analyze the model with constant aggregate labor productivity in more detail. Since most aggregate variables only depend on aggregate productivity (and not on the employment rate), we can analyze the effects of parametric changes in aggregate productivity or unemployment benefits on variables such as market tightness $\theta$. Shimer (2005a) has emphasized that a comparate steady state analysis can provide a good approximation to the dynamics of the matching model, because the dynamic model quickly reaches the new flow equilibrium after a shock.

We first state the model equations in Section 2.3.1. In Section 2.3.2 we show that, under Assumptions ConstB and EtaChi, our model yields the same predictions about wages and labor market tightness as the standard matching model with constant participation. This result is used in Section 2.3.3 to make an important point: endogenous participation makes employment more variable and unemployment 
less variable. Since the standard model underpredicts the variability of both series in comparison to US data, we can say that endogenous participation helps to explain employment dynamics and makes it harder to explain unemployment dynamics. In Section 2.3.4 we drop Assumption ConstB. We show that in this case, a change in productivity or unemployment benefits changes the composition of the unemployment pool. We investigate how this affects the dynamics of labor market tightness, and show that endogenous participation reinforces the critique of the standard matching model found in Costain and Reiter (2003) and Shimer (2005a).

\subsubsection{Recursive formulation of the model}

Standard techniques can be used to show that the value of being non-employed satisfies the following recursive equation:

$$
r V^{n}(h)=\eta\left(\overline{V^{n}}-V^{n}(h)\right)+\max \left\{b(h)+\lambda\left(V^{e}(h)-V^{n}(h)\right), h\right\}
$$

where $\overline{V^{n}} \equiv \int_{-\infty}^{\infty} V^{n}(h) d F(h)$ denotes the expected value of being non-employed, conditional on a redraw of home productivity. The first alternative in (7) is realized if the worker decides to participate in the labor market (unemployed), the second alternative if she decides to stay at home (out of the labor force). It is straightforward to show that the solution of the maximization problem is characterized by a threshold level $h^{c}$, where the non-employed are indifferent between searching or not. This threshold satisfies

$$
h^{c}=b\left(h^{c}\right)+\lambda\left(V^{e}\left(h^{c}\right)-V^{n}\left(h^{c}\right)\right) .
$$

At the threshold, the flow utility from home production is equal to unemployment benefits plus home production under search, plus the value of the chance of finding a job. A household participates in the labor market if its home productivity is below the threshold level. Similarly, the flow value of being employed and the flow value of a filled job satisfy

$$
\begin{aligned}
r V^{e}(h) & =w(h)+\chi\left(\overline{V^{n}}-V^{e}(h)\right) \\
r J(h) & =z-w(h)+\chi(0-J(h)) .
\end{aligned}
$$

The first order condition for the generalized Nash bargaining solution can now be written as

$$
\alpha J(h)=(1-\alpha) \Sigma^{W}(h)=(1-\alpha)\left(V^{e}(h)-V^{n}(h)\right) .
$$

In the absence of aggregate shocks a worker with home productivity $h<h^{c}$ will always participate, therefore his threatpoint could directly be written as the value of a non-employed searcher. 
Free entry implies that expected hiring costs equal the expected value of a filled job:

$$
\frac{\phi}{q(\theta)}=\int_{-\infty}^{h^{c}} J(h) d F(h) \frac{1}{F\left(h^{c}\right)} .
$$

The steady state is then characterized by the six equations (7)-(12) in the unknown functions $V^{n}(h), V^{e}(h), J(h), w(h)$ and variables $h^{c}$ and $\theta$.

\subsubsection{The equilibrium wage and labor market tightness}

Similarly to the standard textbook model, the steady state of the model is characterized by the wage curve (WC):

$$
\begin{aligned}
w(h) & =\frac{r+\eta+\lambda}{r+\eta+\alpha \lambda} \alpha z+\frac{r+\chi}{r+\eta+\alpha \lambda}(1-\alpha) b(h)+(\eta-\chi) \Psi\left(h^{c}\right) \\
\Psi\left(h^{c}\right) & \equiv \frac{r}{r+\eta+\alpha \lambda}(1-\alpha) \overline{V^{n}}
\end{aligned}
$$

and the job creation condition (JCC):

$$
\int_{-\infty}^{h^{c}} w(h) d F(h) \frac{1}{F\left(h^{c}\right)}=z-\frac{\phi}{q(\theta)}(r+\chi) .
$$

The derivation is in Appendix A. WC differs from the standard model in two ways. First, the wage of a worker depends on her idiosyncratic home productivity through $b(h)$. Second, the term $(\eta-\chi) \Psi\left(h^{c}\right)$ captures the effect that having a job changes a worker's chances of redrawing home productivity, which was discussed in Section 2.2. Through this additional term, the endogenous threshold level $h^{c}$ enters the WC. For this reason - unlike in the standard model - we cannot use Equs. (13) and (14) to fully solve for the wage $w$ and labor market tightness $\theta$.

Both problems disappear if we adopt Assumptions ConstB and EtaChi. With $\eta=\chi$, the last term drops out of the wage curve (13), and with it any reference to $h^{c}$. Assumption ConstB eliminates home productivity from the flow utility of unemployment: $b(h)$ in (13) is replaced by $b_{0}$, and it becomes obvious that the wage is the same for all workers. Then it is irrelevant for the firm who it is matched to, and (13) and (14) simplify to

$$
\begin{array}{ll}
\text { WC: } & w=\frac{r+\lambda+\chi}{r+\chi+\alpha \lambda} \alpha z+\frac{r+\chi}{r+\chi+\alpha \lambda}(1-\alpha) b_{0} \\
\text { JCC: } \quad w=z-\frac{\phi}{q(\theta)}(r+\chi) .
\end{array}
$$

Equations (15) and (16) are independent of the participation decision. From here it is easy to derive the aggregate wage equation for the standard textbook model (Pissarides, 2000, Eq. 1.20). We therefore obtain 
Proposition 1 (Equivalence). Under Assumptions ConstB and EtaChi, the steady states and comparative statics of labor market tightness and wages are identical to those in the model with constant, exogenous labor market participation.

\subsubsection{Employment and unemployment}

The equivalence result of the last section allows us to disentangle the dynamics at the employment/unemployment margin - which has been the focus of many papers - from the dynamics at the participation margin, the focus of our paper.

Proposition 2 (Stocks). Under the assumption EtaChi, the steady state stocks of employment, unemployment, and participation are given by:

$$
\begin{aligned}
& e=\frac{\lambda}{\chi+\lambda} F\left(h^{c}\right) \\
& u=\frac{\chi}{\chi+\lambda} F\left(h^{c}\right) \\
& p=F\left(h^{c}\right) .
\end{aligned}
$$

Equ. (17) can be interpreted as follows. The probability of being employed equals the probability of participating in the labor market $\left(F\left(h^{c}\right)\right)$ times the probability of being employed, conditional on participation, $\frac{\lambda}{\chi+\lambda}$. From Proposition 1 we know that the conditional probability is the same as in the standard matching model, and is procyclical (increasing in $z$ ). It is quite obvious (and will be shown formally in Proposition 4) that participation $F\left(h^{c}\right)$ is also procyclical. The participation margin therefore makes employment even more procyclical. The interpretation of (18) is analogous. The probability $\frac{\chi}{\chi+\lambda}$ of being unemployed, conditional on participation, is anticyclical. Procyclical participation then dampens the unemployment fluctuations.

Notice that the intuitive result (19) depends in fact on Assumption EtaChi. If $\eta \neq \chi$, households with low home productivity, which are typically employed, have a different redraw probability than households with high home productivity. This gives a more complicated dynamics of the cross-sectional density of home productivity, which destroys (19).

\subsubsection{The effect of the participation threshold on tightness}

The aim of this section is to investigate how changes in market productivity or the unemployment benefit affect labor market tightness and the participation threshold $h^{c}$. Dropping Assumption ConstB, the next proposition shows that endogenous participation adds an important element to the dynamics of labor market tightness. 
In the following propositions, $\mathrm{d} x$ denotes the change in the equilibrium value of any variable $x$. We write the flow utility of unemployment as $b(h)=b_{0}+b_{1}(h)$, such that the term $\mathrm{d} b_{0}$ means an upward shift of the function $b(h)$.

Proposition 3 (Tightness). Assume EtaChi. Then

$$
\frac{d \theta}{\theta}=\frac{r+\chi+\alpha \lambda}{\vartheta(r+\chi)+\alpha \lambda} \frac{d z-d b_{0}-B^{\prime}\left(h^{c}\right) d h^{c}}{z-B\left(h^{c}\right)}
$$

where

$$
B(h) \equiv \frac{1}{F(h)} \int_{-\infty}^{h} b(\tilde{h}) d F(\tilde{h}) .
$$

Again, under Assumption ConstB, Equ. (20) reduces to the standard formula (e.g. Mortensen and Nagypal (9/2005, Equ. (10))). Before drawing further conclusions from Proposition 3, we first derive the reaction of $h^{c}$.

Proposition 4 (Procyclical Participation). Assume EtaChi holds. Then the general equilibrium response $d h^{c} / d z$ satisfies

$$
\frac{d h^{c}}{d z}=\frac{\alpha \lambda}{(\vartheta(r+\chi)+\alpha \lambda)} \quad \text { if } \quad b(h) \equiv b_{0}
$$

and

$$
\frac{\alpha \lambda}{r+\chi+\alpha \lambda \frac{r+\chi+\alpha \lambda}{\vartheta(r+\chi)+\alpha \lambda}} \leq \frac{d h^{c}}{d z} \leq \frac{r+\chi+\alpha \lambda}{\vartheta(r+\chi)+\alpha \lambda} \quad \text { in general. }
$$

Furthermore, the general equilibrium response $d h^{c} / d b_{0}$ satisfies

$$
\frac{d h^{c}}{d b_{0}}=\frac{(r+\chi) \vartheta}{(\vartheta(r+\chi)+\alpha \lambda)} \quad \text { if } \quad b(h) \equiv b_{0}
$$

and

$$
\frac{\vartheta(r+\chi)}{(r+\chi) \frac{(\vartheta(r+\chi)+\alpha \lambda)}{(r+\chi+\alpha \lambda)}+\alpha \lambda} \leq \frac{d h^{c}}{d b_{0}} \leq \frac{r+\chi}{\alpha \lambda} \quad \text { in general. }
$$

As one would expect, the threshold level of home productivity $h^{c}$ is procyclical. More precisely, $h^{c}$ increases in $z$ with a coefficient that is smaller than but close to unity, since $\lambda>>r+\chi$ in a realistic calibration, and $\alpha=\vartheta$ is assumed. Moreover, Proposition 4 illustrates that $h^{c}$ increases in $b_{0}$. Higher utility while unemployed makes it more attractive to look for a job as compared to staying at home. However, with $\lambda>>r+\chi$ and $\alpha=\vartheta$, we see that $\frac{d h^{c}}{d b_{0}}$ is close to zero.

The essence of Shimer (2005a)'s critique of the matching model with constant participation is that for standard values of $B(h) / z$, the elasticity of $\theta$ w.r.t. $z$ implied by (20) is smaller than 2 , while the data suggest a value of $19.1 .{ }^{6}$ Costain and Reiter

\footnotetext{
${ }^{6}$ Mortensen and Nagypal (9/2005, Section 3) claim that a reasonable estimate of this elasticity is 7.56 rather than 19.1; this argument assumes, however, that a large part of unemployment variations is not caused by productivity shocks but by variation in interest rates, vacancy costs etc.
} 
(2003) have stressed that this elasticity depends crucially on the match surplus: with higher utility of the unemployed $B\left(h^{c}\right)$ the instantaneous match surplus $z-$ $B\left(h^{c}\right)$ gets smaller. This means that the surplus is a more highly leveraged function of productivity $z$, and therefore the elasticities of the surplus and of vacancy creation get bigger. This effect can be easily seen in the denominator of (20). However, they conclude that this is not the solution of Shimer's problem, because a smaller match surplus implies an elasticity of market tightness with respect to $b_{0}$ that is much bigger than what can be inferred from the data. On the other hand, Hagedorn and Manovskii (2005) argue that the correct calibration of the matching model does indeed imply a tiny match surplus for the marginal worker. We will evaluate their argument in detail in Section 5.

What does endogenous participation add to this discussion if we drop the assumption $b(h) \equiv b_{0}$ ? The punchline is that the critique of Shimer (2005a) and Costain and Reiter (2003) becomes even stronger. The intuition is simple: when market productivity increases, workers with higher home productivity enter the labor market. This tends to reduce the average match surplus, and therefore dilutes the effect of higher productivity on vacancy creation.

To evaluate this quantitatively, it is instructive to study the following special case. Assume that the redraw density $F(h)$ is uniform on the interval $\bar{h} \pm \sigma$, and that $b(h)=h-\kappa$. This means that unemployed households enjoy the full home productivity but face the constant search cost $\kappa$. In this case we obtain ${ }^{7} B^{\prime}\left(h^{c}\right)=$ $1 / 2$. From Proposition 4 we know that approximately $d h^{c} \approx d z$. Using this, the term in $z$ on the rhs of Equ. (20) is reduced from $z$ to $z / 2$; the elasticity of tightness with respect to productivity is cut by half. On the other hand, since $\frac{d h^{c}}{d b_{0}}$ is small, the elasticity of $\theta$ with respect to $b_{0}$ is about the same as in the model without participation decision. The dilemma identified by Costain and Reiter (2003), that either the elasticity with respect to $z$ is too low, or that with respect to $b_{0}$ too high, is therefore magnified by a factor of 2 . The numerical results of Section 4.4 will illustrate that the same logic applies to the cyclical variability of unemployment. One can argue that the assumptions leading to $B^{\prime}\left(h^{c}\right)=1 / 2$ are extreme; we will

\footnotetext{
${ }^{7}$ Since the participation rate $P$ equals $F\left(h^{c}\right)$, we get that $\bar{h}-\sigma=h^{c}-2 P \sigma$. Then we get

$$
B\left(h^{c}\right)=\frac{1}{P} \int_{h^{c}-2 P \sigma}^{h^{c}}(h-\kappa) \frac{1}{2 \sigma} d h=h^{c}-\kappa-P \sigma
$$

Differentiation of (21) gives $B^{\prime}(h)=\frac{f(h)}{F(h)}[b(h)-B(h)]$. Using (26), this gives $B^{\prime}\left(h^{c}\right)=1 / 2$. Interestingly, this does not depend on the dispersion parameter $\sigma$. The intuition is the following. The bigger the dispersion $\sigma$, the greater is the difference in home productivity between the average and the marginal unemployed. On the other hand, higher dispersion means that fewer workers enter the labor market after a change in $h^{c}$. In the special case considered, the two effects exactly cancel.
} 
discuss this in more depth in Section 4.4.

\subsection{Variable productivity: the differentiated-wage model}

Allowing for variable aggregate labor productivity increases the complexity of the model substantially. The main difficulty lies in the fact that workers with different home productivities will negotiate different wages, for two reasons. First, they may get different flow utilities during job search, which affects their outside option. Second, even if ConstB is assumed, those with higher home productivity may return to home production when the aggregate state deteriorates, while others will always stay in the labor market. Workers are therefore not homogeneous from the viewpoint of the firm, and when deciding on whether to post a vacancy, a firm has to consider the current composition of the unemployment pool. The zero profit condition for vacancy creation involves an integral over the cross-sectional distribution of home productivity $(\Gamma(h ; t))$ among the non-employed:

$$
\phi(t)=q(t) \int_{-\infty}^{h^{c}(t)} J(h, t) d \Gamma(h ; t) / \int_{-\infty}^{h^{c}(t)} d \Gamma(h ; t) .
$$

Technically, this means that the current cross-sectional distribution of the home productivity of the non-employed becomes a state variable, and techniques similar to the one used in Krusell and Smith (1998) have to be used. This model, which we call the "Differentiated-wage (DW) model", is fully described in Appendix B, and numerical results will be presented in Section 4.4. No interesting conclusions can be obtained analytically for this model. We are therefore going to present a simplified model in the next section.

\subsection{Variable productivity: the equal-wage model}

We think that it is very useful to have a simple workhorse model available that is tractable, but yields qualitatively the same solutions as the complicated DWmodel. The purpose of the present section is to develop such a model. We will make assumptions that guarantee that all workers get the same wage, and we will call the model the "Equal-wage (EW) model". In Section 4 we will compare the models numerically, and we will see that the EW model is indeed a good approximation to the DW model.

To make sure that all workers receive the same wage, we first need Assumption ConstB. Second, we need the following new assumption:

Assumption 3 (ResetH). The unemployed worker loses her current level of home productivity in the moment she is matched to an employer. Instead, she receives a new level $\mathrm{h}$ 
which is small enough that she participates in the labor market under all possible realizations of the exogenous shock $z$.

The worker keeps this level of home productivity until the next redraw, which in case of employed workers is the time of separation from the match. The exact level of $h_{0}$ is irrelevant, since the worker keeps participating in any case and receives $b_{0}$. The purpose of the assumption is to make sure that all workers have the same threat point in the negotiation, so that they receive the same wage, and that firms who post a vacancy do not care which worker they will be matched to. The technical assumption that workers get their home productivity reduced on matching is artificial, but is equivalent to a setup where the median worker - who always participates - determines the wage (e.g. because of unobservable home productivity $)^{8}$. With Assumptions ConstB and ResetH, the outside option of the worker depends only on $b_{0}$, which is the same for all workers. For the purposes of the firm, all the workers are identical at the moment they get matched, and they receive the same wage. Therefore, firms do not have to take the composition of the unemployment pool into account when making a vacancy posting decision.

The formulas characterizing equilibrium are slight modifications of the ones we have seen in Section 2.3. It turns out that with equal wages, all the value functions, as well as labor market tightness and the wage, are functions of the exogenous aggregate productivity only. For example, $V_{i}^{n}(h)$ denotes the value of a non-employed household with home productivity $h$ if the aggregate productivity is $z_{i}$. This value satisfies (recall the notation $p_{i, j}$ from Section 2.1.3):

$$
r V_{i}^{n}(h)=\eta\left(\overline{V_{i}^{n}}-V_{i}^{n}(h)\right)+\sum_{j} p_{i, j} V_{j}^{n}(h)+\max \left\{b_{0}+\lambda_{i}\left(V_{i}^{e}-V_{i}^{n}(h)\right), h\right\} .
$$

The solution to the choice problem in (28) is that households stay at home if their home productivity is greater than the threshold level

$$
h_{i}^{c}=b_{0}+\lambda_{i}\left(V_{i}^{e}-V_{i}^{n}\left(h_{i}^{c}\right)\right) .
$$

The value of the employed is

$$
r V_{i}^{e}=w_{i}+\chi\left(\overline{V_{i}^{n}}-V_{i}^{e}\right)+\sum_{j} p_{i, j} V_{j}^{e}
$$

\footnotetext{
${ }^{8}$ We could also assume that before taking on a job (even before negotiating with the employer) the worker has to undergo an investment in human capital that will remain with him until the next redraw (which means, he loses his job). If this investment is big enough, once the worker is matched with an employer, she does not want to leave the labor market under any realization of aggregate productivity, before she redraws her home productivity. In this case, only the utility flow of the unemployed affects her outside option.
} 
and the value of a filled job is

$$
(r+\chi) J_{i}=z_{i}-w_{i}+\sum_{j} p_{i, j} J_{j}
$$

The first order condition for the Nash bargaining solution is

$$
\alpha J_{i}=(1-\alpha) \Sigma_{i}^{W}\left(h_{0}\right)
$$

where $\Sigma_{i}^{W}(h) \equiv\left(V_{i}^{e}-V_{i}^{n}(h)\right)$. Finally, we have the zero profit condition for vacancy creation:

$$
J_{i}=\frac{\phi}{q\left(\theta_{i}\right)} .
$$

The model solution is characterized by equations (28)-(33) in the unknown functions $V_{i}^{n}(h), V_{i}^{e}, J_{i}, w_{i}$ and variables $h_{i}^{c}$ and $\theta_{i}$.

If we add Assumption EtaChi, we get rewarded with a very tractable model:

Proposition 5. Under Assumptions ConstB, EtaChi and ResetH, the wage $w_{i}$, the labor market tightness $\theta_{i}$ and the critical home productivities $h_{i}^{c}$ are independent of the redraw distribution $F(h)$.

Proof. Since we have assumed that $h_{0}<h^{c}$ for all $i$, a worker with $h_{0}$ always participates, and her surplus satisfies

$$
r \Sigma_{i}^{W}\left(h_{0}\right)=w_{i}-b_{0}-\lambda_{i} \Sigma_{i}^{W}\left(h_{0}\right)+\sum_{j} p_{i, j} \Sigma_{j}^{W}\left(h_{0}\right)+\chi\left(\overline{V_{i}^{n}}-V_{i}^{e}\right)-\eta\left(\overline{V^{n}}-V_{i}^{n}\left(h_{0}\right)\right) .
$$

Under Assumption EtaChi, this simplifies to

$$
\left(r+\chi+\lambda_{i}\right) \Sigma_{i}^{W}\left(h_{0}\right)=w_{i}-b_{0}+\sum_{j} p_{i, j} \Sigma_{j}^{W}\left(h_{0}\right) .
$$

Equations (31), (32), (33) and (35) are a system of $4 N_{z}$ equations which determine the $4 N_{z}$ unknowns $w_{i}, \theta_{i}, \Sigma_{i}^{W}\left(h_{0}\right)$ and $J_{i}$. The redraw distribution $F(h)$ does not enter these equations. The $h_{i}^{c}$ can then be determined by solving (28).

Equations (31), (32), (33) and (35) are equivalent to the equations in the standard matching model (Mortensen and Nagypal, 9/2005, Section 2). That means that this simplified model has implications for labor market tightness, job finding probabilities and wages that are equivalent to the basic model. Again, what differs from the basic model is the dynamics of the stocks of employment and unemployment. This has already been explained in the comparative steady state analysis of Section 2.3.

Our model is as easy to analyze as the standard Pissarides model. In the following subsections we exploit this fact and first discuss existence and uniqueness of equilibrium. Then we will establish that the model contains the Pissarides model as a special case. The numerical results of Section 4 will show that the quantitative effect of Assumptions ConstB, EtaChi and ResetH is relatively small, so that we are not making a big mistake by resorting to the simple EW model. 


\subsubsection{Existence and uniqueness of equilibrium}

For some parameter values, in particular those where household productivity is higher than unemployment benefits $b_{0}$ with probability 1 , there exists a degenerate equilibrium where no firm posts vacancies, because no worker searchers for a job, and no worker searchers for a job because no firm posts a vacancy. We are not interested in this type of equilibrium, but only look at equilibria where there is positive employment and search in all aggregate states. Existence of such an equilibrium depends on parameters. Obviously, if home productivity for all workers is higher than market productivity, there will be no such equilibrium. If there is an equilibrium with vacancies and search in all aggregate states, we have seen that the model under Assumption EtaChi is equivalent to the basic Pissarides model with respect to the variables wages and labor market tightness. For a proof of uniqueness and existence of equilibrium in this model, see Mortensen and Nagypal (9/2005, Proposition 1).

\subsubsection{The limit of constant participation}

Under Assumptions ConstB, EtaChi and ResetH, our model reduces to the standard matching model with constant participation if the redraw distribution $F(h)$ has zero mass in the critical range.

To see this more formally, note first that Proposition 5 says that the critical values $h_{i}^{c}$ are independent of the redraw distribution $F(h)$. Define $h_{\min }^{c} \equiv \min _{i} h_{i}^{c}$, and $h_{\max }^{c}$ accordingly. Under Assumption EtaChi, it is readily shown ${ }^{9}$ that $\Gamma\left(h_{\max }^{c} ; t\right)=$ $F\left(h_{\max }^{c}\right)$ at any time $t$. Now assume that $F(h)$ has zero mass in the range where participation depends on the aggregate state: $F\left(h_{\max }^{c}\right)=F\left(h_{\min }^{c}\right)$. Then it follows that $\Gamma\left(h_{\min }^{c} ; t\right)=F\left(h_{\max }^{c}\right)$ for all $t$, and the participation rate is constant at $P(t)=F\left(h_{\max }^{c}\right)$.

We will later study the case where the redraw distribution is uniform in $\bar{h} \pm \sigma$. The model with constant participation is obtained for $\sigma \rightarrow \infty$.

\footnotetext{
${ }^{9}$ Consider any set $H$ with $h \geq h^{c}(t)$ for all $h \in H$. In the case $\chi=\eta$, the cross-sectional distribution $\Gamma(H ; t)$ then follows the differential equation

$$
\frac{d \Gamma(H ; t)}{d t}=-\chi \Gamma(H ; t)+\chi F(H)
$$

If the economy starts out with $\Gamma(H ; 0)=F(H)$, then Equation (36) implies that $\Gamma(H ; t)$ is constant, and therefore $\Gamma(H ; t)=F(H)$. Notice that the term $\chi F(H)$ in (36) is a consequence of the assumption $\chi=\eta$; if the employed redraw at a different rate than the non-employed, the dynamics of the cross-sectional density is more complicated and depends on the current unemployment rate.
} 


\subsection{Rigid wages}

Several recent papers (Costain and Reiter, 2003; Hall, 2005; Shimer, 2005a) have stressed that the failure of the standard matching model to explain the observed dynamics of unemployment may be due to the assumption of Nash bargaining. Introducing some kind of real wage rigidity generates much higher unemployment volatility in the model and brings it closer to the data. Wage rigidity is not the focus of our paper, and we do not provide any microfoundation for real wage rigidity ${ }^{10}$. We illustrate that some degree of real wage rigidity helps to bring the model much closer to the data, just as for the standard matching model without a participation margin. The key aspect of wage rigidity is that firms get a bigger share of the total surplus during booms, such that they have a bigger incentive to hire workers. To capture this in the simplest possible way, we assume that the firms' bargaining share is higher in booms than in recessions. Besides simplicity, this formulation has the advantage that it guarantees privately efficient job separations.

\section{Data and Calibration}

This section briefly documents the time series behavior of unemployment, employment, and labor force participation in relation to output in the United States. Using these data, we then turn to the calibration of our model.

\subsection{Data}

Our data series range from January 1976 to December 2001. Table 1 summarizes the detrended data. Aggregate data on unemployment, employment, and participation has been obtained from the Bureau of Labor Statistics. As a robustness check we also compute the same statistics based on CPS micro data for the population aged 16 to 65 . The message is basically the same (as can be seen from Table 1). We base the paper on the BLS numbers because they are computed for the entire population - which is the set of agents consistent with our data on GDP and other macroeconomic aggregates. Following Shimer (2005a), we remove a very low frequency trend from the data, applying a Hodrick Prescott (HP) filter with a smoothing parameter of 100000 to the logarithm of our quarterly data. We see that, over our sample, the percentage change of the unemployment rate has a standard deviation of 0.145 or seven times as large as GDP. These results are similar to Shimer's who finds 0.19 . It is also widely agreed upon that detrended unemployment ex-

\footnotetext{
${ }^{10}$ Some interesting recent contributions include Hall and Milgrom (2005) and Kennan (2005).
} 
hibits very high persistence with quarterly autocorrelation of 0.968 . The detrended unemployment rate is strongly countercyclical as evidenced by a contemporaneous correlation coefficient with GDP of -0.9.

Another important indicator of labor market activity is the employment rate (employment/population ratio) which averages $61.2 \%$ over our sample. It is strongly procyclical (it exhibits a contemporaneous cross-correlation with GDP of 0.9) and highly persistent (autocorrelation is 0.96 ), with a variability of about two thirds of that of GDP.

The average participation rate over our sample period is $65.35 \%$. Persistence is high (0.86), but slightly lower than for the employment and unemployment series. The log-detrended participation rate is procyclical (correlation with GDP is 0.5) and its standard deviation is $23 \%$ of output variability, or about one third of employment variability. It is important to note that our analysis focuses on the entire working age population of both sexes rather than restricting ourselves to certain age groups as the previous papers in this literature (Faraglia, 2003; Garibaldi and Wasmer, 2005) have done. While the precise numbers we report are not identical to theirs, the qualitative picture remains the same.

\subsection{Calibration}

This section describes the calibration of all the parameters in the benchmark models. Besides studying a benchmark case, we are going to vary several parameters $\left(\sigma, b, r, \rho_{z} \alpha, \vartheta, \eta\right)$ systematically and document the influence that they have on the equilibrium.

The benchmark calibration, which applies equally to the flexible and the rigid wage model, is summarized in Table 2. Numbers referring to flows are at quarterly rates. The interest rate is 1.2 percent quarterly. For the process of aggregate productivity, we choose a 15-state Markov chain that approximates the AR(1) process

$$
z_{t+1}=\rho_{z} z_{t}+\varepsilon, \quad \varepsilon \sim N\left(0, \sigma_{\varepsilon}^{2}\right) .
$$

We follow Cooley and Prescott (1995) and many papers in the RBC tradition and choose $\rho_{z}=0.95$ as our benchmark calibration. This facilitates the comparison of the shock propagation in our model with the results in the RBC literature. However, since this parameter turns out to be important for the variance of labor market participation, we run a series of experiments varying $\rho_{z}$ between 0.5 and 0.99 . In each case, we choose $\sigma_{\varepsilon}=0.0125 \sqrt{\left(1-\rho_{z}^{2}\right)}$ which gives an unconditional variance of $z$ of 0.0125 (before filtering). The variance of $z$ was chosen to approximately match the variance of GDP in our preferred specification with rigid wages. Keeping this 
variance constant allows us to compare the magnification effects across different specifications. Average productivity is always normalized to unity.

We normalize the efficiency parameter $\mu$ in the matching function to 1 , which implicitly scales the number of vacancies but otherwise has no real consequences. Following much of the literature, we set the elasticity parameter $\vartheta$ in the Cobb Douglas matching function to 0.5 , and we pick the worker's bargaining power to equal the matching elasticity $\alpha=\vartheta=0.5$ (Hosios condition).

The separation rate, $\chi$ is observed directly in our data and is equal to $9.9 \%$ quarterly. This choice is consistent with the values reported in Shimer (2005a) and Abowd and Zellner (1985). In each experiment, the median home productivity $\bar{h}$ and the vacancy posting cost $\phi$ are chosen to match a steady state participation rate of $65.35 \%$ and an unemployment rate of $u=6.37 \%$. As explained in Section 2, we set $\eta=\chi$.

\section{The flow utility of unemployment $b$}

Shimer (2005a) chooses to interpret $b$ entirely as unemployment benefit and sets it to approximately $40 \%$ of mean labor income. More generally, we must allow for some level of home productivity or utility of leisure, as well as the disutility of searching for a job. Thus, a priori it is hard to say what this number is. Costain and Reiter (2003) propose to calibrate this number such that the model generates the correct response of the steady state unemployment rate to long-run changes in the unemployment benefit. They cite a semi-elasticity of unemployment w.r.t. benefits $b$ of 1.3 as the best point estimate. In our model, we achieve this target by setting $b=0.615$.

\section{The distribution of home productivity and aggregate labor supply}

The redraw distribution of home productivity $F(h)$ is hard to calibrate. In reality, this distribution may have multiple modes, corresponding to different groups of the population. What matters for our analysis is not the shape of the total distribution, but only the mass of agents near the threshold. Several recent articles (den Haan, 2005; den Haan, Haefke, and Ramey, 2005; den Haan, Ramey, and Watson, 2000) have stressed this point in related models. We therefore start from the simplest setup and assume a distribution with constant density, that means, a uniform distribution in $(\bar{h}-\sigma, \bar{h}+\sigma){ }^{11}$

\footnotetext{
${ }^{11}$ We have redone the analysis with a lognormal home productivity; this doesn't change any relevant conclusion.
} 
We have explained above how we choose the parameter $\bar{h}$; it remains to find $\sigma$. In our model, it measures the cross-sectional dispersion of home productivity. We have said that in the real world this should be interpreted as the difference between market and home productivity, which we call "relative productivity" from now on. Since we are not aware of any measurement of the cross-sectional dispersion of home productivity, we calibrate the model only through wage data. Furthermore, we measure wage dispersion separately for men and women and calibrate the model by the within-group variation. This appears the most appropriate measure, since gender is a permanent variable, while our home productivity is redrawn.

Therefore, separately for men and women, we define the wage ratio

$$
\phi_{i} \equiv \frac{\text { Wage }\left(3^{\text {rd }} \text { decile }, i\right)-\text { Wage }\left(1^{\text {st }} \text { decile }, i\right)}{\text { Wage }\left(2^{\text {nd }} \text { decile }, i\right)}
$$

where $i$ takes the values $M$ (male) and $F$ (female). We use data on the lower part of the distribution only, because the participation decision is most critical for low wage earners. Then we define $\phi_{d a t a}$ as the average over men and women, weighted by the employment rates:

$$
\phi_{\text {data }}=\left(\text { EmplRate }_{M} \cdot \phi_{M}+\text { EmplRate }_{F} \cdot \phi_{F}\right) /\left(\text { EmplRate }_{M}+\text { EmplRate }_{F}\right)
$$

In the model, we identify this with

$$
\phi_{\text {model }} \equiv \frac{(\text { Wage }-h)\left(3^{\text {rd }} \text { decile }\right)-(\text { Wage }-h)\left(1^{\text {st }} \text { decile }\right)}{\text { Wage }\left(2^{\text {nd }} \text { decile }\right)}
$$

where $h$ is home productivity. Note that we use the same denominator in (39) and (38), namely Wage( $2^{\text {nd }}$ decile), to scale the wage dispersion. Scaling it with $($ Wage $-h)\left(2^{\text {nd }}\right.$ decile $)$ would require to take a stand what average $h$ is in the data, which is not clear. From the data (CPS outgoing rotation groups, average 19761996) of Bernstein and Mishel (1997) we get $\phi_{M}=0.425, \phi_{M}=0.281$ and $\phi_{\text {data }}=0.363$. In each variant of the model, the $\sigma$ is calibrated so as to set $\phi_{\text {data }}=\phi_{\text {model }}$.

Note that the above procedure will give a good approximation to the dispersion of relative productivity if there is little variation in home productivity within each sex group and if there is a slightly positive correlation between market and home productivity which compensates the variation in home productivity. In our benchmark model, this calibration leads to a value of $f(h)=\frac{1}{2 \sigma}=0.424$. If we define labor supply elasticity $\varepsilon_{z}^{P}$ as the elasticity of labor market participation to the change in labor productivity in general equilibrium, we obtain using (19) and (22):

$$
\varepsilon_{z}^{P}=f\left(h^{c}\right) \frac{d h^{c}}{d z} \frac{z}{P}=0.424 \frac{\alpha \lambda}{(\vartheta(r+\chi)+\alpha \lambda)} \frac{1}{0.75}=0.6035 .
$$


A labor supply elasticity of 0.6 lies well in the interval of recent microeconometric estimates which stress the extensive margin (participation decision) of labor supply. Table 3 provides an overview of the most important studies; a broader and very recent overview of the labor supply literature, not necessarily focused on participation, can be found in Alesina, Glaeser, and Sacerdote (2005, Table 7). If anything, our elasticity is somewhat lower than the microeconometric estimates, contrary to common wisdom that assumes that macroeconomic models need higher elasticities than what the microestimates deliver.

\section{Rigid wages}

In the model with flexible wages, $\alpha$ is constant. In the model with rigid wages, we assume $\alpha(t)=0.5-\Delta_{\alpha} \log z(t)$. We see in the data that the wage fluctuations are almost as big as GDP fluctuations, but that the correlation between the two is rather small. Since we are interested in the wage fluctuations only insofar as they are correlated with production, we target the systematic variability of wages $\rho_{w, y} \sigma_{w} / \sigma_{y}$. We choose $\Delta_{\alpha}$ so as to match this target.

\subsection{Simulation}

Our theoretical model is in continuous time, but for simulation purposes we have to discretize it. To stay true to the continuous time spirit, and since labor market flows occur with high frequency, we choose one week as model period - or more precisely, $1 / 48$ of a year. The model is simulated for 1248 weeks, aggregated to 104 quarterly observations corresponding to the data from I/1976 to IV/2001, and detrended using the log of the model-generated data with a smoothing parameter of $10^{5}$. We repeat these simulations 1000 times and report the mean and standard deviations of the model-generated moments. ${ }^{12}$

\section{Numerical Results}

\subsection{Variability of labor market aggregates}

In this section we numerically evaluate the performance of our models. First we investigate whether the model is able to explain the unconditional variances of participation, employment and unemployment. Table 4 describes the data. As a reference point, the first panel in Table 5 reports results for the model with constant

\footnotetext{
${ }^{12}$ Matlab programs for solving and simulating the EW model are available from the authors on request.
} 
participation (cf. Section 2.5.2). The second panel in Table 5 contains the results for the benchmark EW-model with flexible wages. The constant participation version differs from the benchmark only by setting the cross-sectional density around the participation threshold equal to zero. The third panel in Table 5 presents results for the DW-model with flexible wages. It only serves to demonstrate that the EWand the DW- model yield very similar results if Assumption ConstB is imposed, thereby justifying the simplifications that lead to the EW-model.

Three main conclusions emerge. First, the model predicts the right variability of participation relative to GDP, somewhat less that 0.25 . This is remarkable, because our calibration does not target this statistic. As we will demonstrate below, the variability of participation depends mainly on the cross-sectional dispersion of home productivities, $\sigma$, which was calibrated using observed wage data. The second conclusion is that endogenous participation amplifies employment responses, as we expected from Proposition 2. Employment variability (relative to GDP) is more than four times higher with endogenous than with constant participation, but it still falls short of what we see in the data. Third, endogenous participation reinforces the well known inability of the standard matching model to explain the variability of unemployment. This was again expected from Proposition 2. In the data, unemployment is roughly 6 times more volatile than GDP (cf Table 4), whereas the model with constant participation only generates unemployment roughly as volatile as GDP. When allowing for an endogenous participation decision, the ratio of standard deviations falls further to 0.703 . In Figure 2 we demonstrate the robustness of these conclusions to parameter variations.

Since we have analytically shown that the dynamics of employment and unemployment can be neatly separated into the dynamics of tightness and the dynamics of the participation decision (Section 2.3.3), anything that improves the dynamics of tightness in the standard model will also improve the model with endogenous participation. Recently, several ways have been proposed how to bring the matching model more in line with the data. Here we follow the most prominent of these proposals, namely the introduction of wage rigidity (cf. Section 2.6). In Section 5 we will investigate another proposal, namely a calibration with very small match surplus.

Table 6 contains the results with rigid wages. We see that rigid wages increase unemployment variability sevenfold. We now match the variability of participation, employment, unemployment and vacancies quite well. The model generates a strong magnification of productivity shocks, a consequence of the strong fluctuation in employment. The variability of the participation rate is now somewhat 
smaller than in the data, but notice that the systematic variability (standard deviation times correlation with GDP) is still slightly higher in the model than in the data.

From Proposition 2 we know that the crucial statistic that determines participation dynamics is the cross sectional density of home productivity at the participation threshold. A high density implies more inflows into participation when a positive productivity shock hits, which increases employment variability and reduces unemployment variability. The bottom row of Figure 1 clearly illustrates this tradeoff.

\subsection{Cyclicality of unemployment}

Table 6 shows that our model with endogenous participation generates a countercyclical unemployment rate, in line with the data. This must be considered a major success of the model, given that earlier attempts to endogenize participation reported a positive correlation. With flexible wages (Table 5), the negative correlation is not yet strong enough. With rigid wages (Table 6), the correlation is as strong in the model as in the data.

Why does our model succeed where earlier attempts have failed? Three elements are crucial to obtain the strong anticyclical movement of unemployment. The first and most important element is again the cross sectional density of home productivity. If this density is high, the flow from nonparticipation into unemployment after a productivity increase is so big that it takes a lot of time to match the newly unemployed. This leads to a positive correlation of unemployment and GDP, which is evident from the top row of Figure 1. The figure also illustrates the effect of the second element, namely time aggregation. At higher frequencies, the correlation is less negative, because the inflow of new unemployed is measured before they are absorbed into employment. In discrete time models with quarterly time periods this effect is very strong, because people are unemployed for at least a quarter. Third, a stronger reaction of tightness, and therefore hiring, makes that the newly unemployed get absorbed faster, so that the negative correlation becomes stronger. This has already been demonstrated by the comparison of the flexible with the rigid wage model.

These results imply an important tradeoff for the calibration of the model: higher cross-sectional density helps to match employment fluctuations, but it reduces the fluctuation of unemployment, and tends to make the correlation between unemployment and production positive. For example, Veracierto (2004) calibrates his model so as to match the variability of employment, which implies a high labor 
supply elasticity. ${ }^{13}$ This explains why the model generates procyclical unemployment.

\subsection{Dynamic Responses}

Recently it has been argued that a model may well match unconditional moments but yet provide a distorted picture of an economy's dynamic response to individual shocks (Galí, 1999). In Figure 3 we illustrate the response of our model to a unit shock in observed labor productivity. In the first column we see that employment basically does not respond in the standard, constant-participation model, whereas there is a significant increase in the data. The endogenous participation decision (column 2) substantially improves employment responses, and finally wage rigidity (columns 3) bring the magnitude of the employment response in line with the data. It is worth noting that the model is able to generate the hump-shaped response observed in the data. However, with rigid wages the model probably reacts to strongly on impact. The flipside is of course that wages respond too strongly in the flexible wage model. Even in the rigid wage case the wage response is too strong, although we have calibrated the model to match the systematic wage variation. This difference can arise because impulse response functions measure conditional covariances, while we have matched the unconditional covariance.

Let us turn to the focus of this paper, the dynamics of participation. The magnitude of the response of the participation rate is well captured both by the flexible and the rigid wage model. Again, the response is more delayed in the data than in the model.

\subsection{Composition Effects}

If we drop Assumption ConstB, we know from the discussion of Proposition 3 that changes in aggregate productivity change the composition of the unemployment pool, and thereby affect the incentives for firms to create vacancies. To illustrate these effects most drastically, we now adopt a specification that is the opposite extreme of Assumption ConstB: we assume that households enjoy their full home production even while looking for a job; they only face a constant search cost of 20 percent of average labor productivity. That means, $b(h)=h-0.2$. Otherwise, the specification is unchanged. The results can be found in the bottom panel of Ta-

\footnotetext{
${ }^{13}$ Veracierto does not allow for heterogeneity across workers. Decisions in his model are taken by a representative household with many members. Labor supply elasticity is determined by the curvature of the utility function.
} 
ble 5. The model now produces strongly counterfactual results, the unemployment rate being procyclical. What happens after a positive productivity shock? More people enter the labor market; since they are marginal, their surplus from a job (the difference between home and market productivity) is small. Since the match surplus is shared between firm and worker, this tends to decrease the expected return from a filled vacancy, therefore dampening even more the positive effect of a productivity shock on vacancy creation. This is what we expect after the discussion of Section 2.3. It manifests itself as an increased variability of wages, and a strongly decreased variability of vacancies. The additional vacancies in a boom are not sufficient to absorb the additional labor market participants, and unemployment becomes procyclical.

We interpret this outcome not as a result of how the participation decision is modeled, but yet again as a consequence of the wage determination mechanism. In a boom, very little of the additional production is left for firms as an incentive for vacancy creation. Endogenous participation, in this variant of the model, amplifies this shortcoming. Our specification with rigid wages tries to overcome this problem, although in a simplistic way. We can do the same thing here, using the same degree of bargaining power variation. The results are in the bottom panel of Table 6 . Comparing this to the middle panel we still see the same mechanism at work: the increased share of marginal workers in booms dampens the unemployment fluctuations. But now we are only talking about quantitative details, not the qualitative picture. Unemployment variability relative to GDP is reduced from 5.2 to 4.8 , and the unemployment rate is still almost perfectly negatively correlated with GDP. The simple model appears to be a good approximation to the general model. Whether those quantitative details make it worthwhile to undergo the technical complications of the full model will depend on the purpose of the exercise.

\section{How important are composition effects?}

If the unemployed are heterogeneous ( $b(h)$ not constant), aggregate fluctuations induce changes in the composition of the unemployment pool. In booms, workers with higher home productivity enter the labor market. This tends to reduce the average match surplus, and therefore dilutes the gains from higher productivity for firms. This further dampens the variability of labor market tightness over the business cycle, which is already too low in the model with exogenous participation. How important is this composition effect in reality? Insofar as workers differ in home productivity, as assumed in our model, the effect is probably real, since the assumption $b(h)=b_{0}$ appears hard to justify; even when searching for a job, 
workers do probably enjoy most of their home productivity.

If in reality most of the heterogeneity among workers comes through differences in market wages, there is no reasonable analogue to Assumption ConstB. New entrants will have a smaller job surplus than workers already in the market. To what extent this affects vacancy creation will depend on the degree of market segregation. Low wage earners entering the market will mostly compete with workers earning a marginally higher wage, not with high wage earners from a different profession. Then the average match surplus in each market will change little over the cycle. Based on this, we conjecture that the composition effect and the resulting dampening of vacancy creation is much less severe in reality than in our DW-model with $b(h)=h-0.2$. Still, it is clear that endogenous participation makes it harder to explain unemployment fluctuations, not easier.

\subsection{Labor Market Flows}

Table 8 compares average labor market flows in the data and in the benchmark model. We see that the model does not do well in explaining these flows. The most important failings are the following. First, the model grossly underpredicts the flow from nonparticipation to employment. In the model, a worker has to become unemployed to have a chance to find a job. The observed flow from nonparticipation to employment only consists of the households that enter the unemployment pool and get a job before they are measured as unemployed (observations of labor market states are monthly). This time aggregation effect, however, explains only $20 \%$ of the observed flow. To fix this, one needs a model where also nonparticipants can look for a job, with a lower intensity than the unemployed.

Second, the model does not explain the big flow from unemployment to nonparticipation. It seems there are many households in the data set that are close to the participation margin, and then switch back and forth frequently. To explain this, the model would have to allow for small temporary fluctuations in productivity, which our model doesn't.

Third, when households separate from a job, 60 percent of them become nonparticipants in the data, but only about 25 percent in the model. To explain this, one probably needs endogenous separation, such that people typically have low market productivity when they separate, as in Garibaldi and Wasmer (2005). 


\section{Small Surplus Calibration}

In a recent paper that has drawn considerable attention, Hagedorn and Manovskii (2005) propose a new calibration of matching models which they claim solves the well known problem of the standard matching model, namely the insufficient variability of the unemployment rate. They propose to increase the variability of unemployment in the model by assuming that the match surplus is very small. ${ }^{14}$ In their calibration, the flow value of unemployment benefits (including the value of leisure when unemployed) is 94.3 percent of labor productivity in steady state.

This may appear implausible, but Hagedorn and Manovskii (2005) justify their calibration, saying that " $\ldots$ our estimate $[\cdots]$ represents the value of unemployment for the marginal worker, who finds employment quickly." Mortensen and Nagypal (9/2005, Section 3.3) have already pointed out that this argument is irrelevant, since what matters is not the surplus of the marginal, but of the average worker. In our model, this can be seen from Equ. (20). Home productivity enters through $B\left(h^{c}\right)$, which is the average home productivity of the unemployed, not the home productivity of the marginal labor market participant. The explanation is obvious: since firms do not know which worker they will be matched to, it is the average home productivity that determines the expected match surplus, and therefore vacancy creation.

In our framework, the idea of a small (average) match-surplus can be implemented in two ways. First, we can adopt Assumption ConstB and say that all the unemployed have the same, very high, flow utility, analogous to the specification in the standard matching framework. Note that this is a very artificial approach. In our calibration, home productivity varies widely, but while searching, all the unemployed get the same flow of utility that is close to the utility of working. If we follow this approach, the theoretical results of Section 2 already tell us that the model is equivalent to the standard model with respect to the fluctuation of the job finding rate. In this case, we are left with the same merits and problems of the model that have already been discussed in other papers (Costain and Reiter, 2003; Mortensen and Nagypal, 9/2005). This is confirmed by the results in the middle panel of Table 7.

Our DW model allows a second, more natural way of implementing the idea

\footnotetext{
${ }^{14}$ Costain and Reiter (2003) had already observed that a small match surplus makes unemployment fluctuate strongly in the standard matching model, but then concluded that this calibration is inappropriate since it implies an extremely high elasticity of unemployment with respect to long-run changes in unemployment benefits, contrary to what one finds in the data. We will see that the same argument applies in the model with endogenous participation.
} 
of a small match surplus. Since the match surplus is about zero for the marginal worker, the average surplus is small if workers are sufficiently homogenous. In our model, heterogeneity is measured by the parameter $\sigma$ - the cross sectional dispersion of the difference between market and home productivity. Small average match surplus then requires a low value of $\sigma$. For concreteness, take the flow utility of the unemployed as $b(h)=0.4+0.5 h$. The 0.4 corresponds to unemployment benefits, and the slope parameter of 0.5 implies that at the critical level of $h \approx 0.95$, the unemployed obtain a similar level of utility as if they were staying at home. We choose $\sigma=0.08$ to obtain an average surplus of about 0.06 as in Hagedorn and Manovskii $(2005)^{15}$. The results for this calibration are given in the bottom panel of Table 7. We see what we had already expected for such a low cross-sectional dispersion of home productivity: labor supply elasticity is very high, and this implies procyclical unemployment. This implementation of the idea of a small match surplus is clearly inconsistent with the data.

\section{Conclusions}

We contribute to the equilibrium unemployment literature by proposing a simple, tractable job matching model with endogenous participation decision. Our model fits micro- and macro evidence well and can be extended in a straightforward manner. In fact it is not harder to solve than the standard Mortensen/Pissarides model. When it comes to matching the business cycle facts of participation, employment and unemployment, our calibration is much more successful than earlier attempts with endogenous participation. We show that a sufficiently low elasticity of labor supply on the extensive margin is necessary to generate countercyclical unemployment rates and avoid the counterfactual implications of the earlier literature.

Compared to a standard matching model with exogenous participation, our model generates a much stronger magnification mechanism of technology shocks by increasing the variability of employment. However, the same mechanism dampens the variability of unemployment and aggravates the well known problem that standard models cannot match unemployment fluctuations well. In an extension we follow some recent papers and introduce real wage rigidity. In this case the model explains the variability and correlation structure of the labor market very well.

\footnotetext{
${ }^{15}$ A participation rate of $75 \%$ and $\sigma=0.08$, imply a spread between the marginal worker and the lower bound of the support of 0.12 . If the marginal worker is indifferent, the average current surplus will be $0.012 \cdot 0.5=0.06$.
} 
The simplicity of our model will allow many extensions (for example physical capital, nominal rigidities) in future work. Two promising avenues are endogenous separations of job matches (den Haan et al., 2000) and household labor supply decisions (Blundell, Chiappori, Magnac, and Meghir, 2005; Faraglia, 2003). 


\section{References}

Abowd, J., and A. Zellner. 1985. Estimating gross labor force flows. Journal of Business and Economic Statistics 3:254-283. 3.2

Alesina, A., E. Glaeser, and B. Sacerdote. 2005. Work and leisure in the U.S. and Europe: Why so different? NBER Macroeconomic Annual 2005 forthcoming. 3.2

Ashenfelter, O. 1978. The labor supply response of wage earners. In Welfare in rural areas, ed. J. Palmer and J. Pechman, vol. ??, ?? Washington, DC: The Brookings Institution.

Bernstein, J., and L. Mishel. 1997. Has wage inequality stopped growing. Monthly Labor Review 3-16. 3.2

Blundell, R., P.A. Chiappori, T. Magnac, and C. Meghir. 2005. Collective labor supply: Heterogeneity and nonparticipation. CEPR Discussion Paper 5287. 6

Chang, Y., and S.B. Kim. 2003a. From individual to aggregate labor supply: A quantitative analysis based on a heterogeneous agent macroeconomy. Federal Reserve Bank of Richmond Working Paper 03-05. 2.1.1

- 2003b. From individual to aggregate labor supply: A quantitative analysis based on a heterogeneous agent macroeconomy. Federal Reserve Bank of Richmond Working Paper 03-05. ht t p: //al cor. concordia.ca/ sunbink/Papers/Laborsupply. pdf.

Cooley, T.F., and E.C. Prescott. 1995. Economic growth and business cycles. In Frontiers of business cycle research, ed. T.F. Cooley, chap. 1. Princeton University Press. 3.2

Costain, J., and M. Reiter. 2003. Business cycles, unemployment insurance, and the calibration of matching models. mimeo, UPF . 2.3, 2.3.4, 2.3.4, 2.6, 3.2, 5, 14

den Haan, W.J. 2005. Temporary shocks and the unavoidable road to high taxes and high unemployment. mimeo London Business School. ht t p: / / facul ty. I ondon. edu/ wdenhaan/ papers/ mul tnew05-03-08. pdf. 3.2

den Haan, W.J., C. Haefke, and G. Ramey. 2005. Turbulence and unemployment in a job matching model. Journal of the European Economic Association 3:1360-1385. 3.2

den Haan, W.J., G. Ramey, and J. Watson. 2000. Job destruction and propagation of shocks. American Economic Review 90:482-498. 3.2, 6 
Faraglia, E. 2003. Search intensity, us gross worker flows and the business cycle. Mimeo, NYU . 1, 3.1, 6

Galí, J. 1999. Technology, employment, and the business cycle: Do technology shocks explain aggregate fluctuations? American Economic Review 89:249-271. 4.3

Garibaldi, P., and E. Wasmer. 2005. Equilibrium search unemployment, endogenous participation and labor market flows. Journal of the European Economic Association 3:851-882. 1, 2.1.1, 2.2, 3.1, 4.5

Hagedorn, M., and I. Manovskii. 2005. The cyclical behavior of equilibrium unemployment and vacancies revisited. Mimeo, presented at SED. 2.3.4, 5

Hall, R.E. 2005. Wage determination and employment fluctuations. American Economic Review 95:50-65. 2.6

Hall, R.E., and P.R. Milgrom. 2005. The limited influence of unemployment on the wage bargain. NBER Working Paper 11245. 10

Jorda, O. 2005. Estimation and inference of impulse responses by local projections. American Economic Review 95:161-182. E

Kennan, J. 2005. Private information, wage bargaining, and employment fluctuations. Mimeo, presented at SOLE . 10

Kim, S.B. 2003. Unemployment insurance policy with endogenous labor force participation. Mimeo, Concordia University . 1

Kimmel, J., and T.J. Kniesner. 1998. New evidence on labor supply: Employment versus hours elasticities by sex and marital status. Journal of Monetary Economics 42:289-301.

Kohn, S. 2004. The outlook for inflation. Remarks by Governor Donald L. Kohn: National Economists Club Luncheon Meeting, Washington D.C. June 4. ht t p: / / www. federal reserve. gov/boarddocs/speeches/2004/20040604/ def aul t. ht m 3

Krusell, P., and A.A. Smith. 1998. Income and wealth heterogeneity in the macroeconomy. Journal of Political Economy 106:867-898. 2.4, B

Mortensen, D., and E. Nagypal. 9/2005. More on unemployment and vacancy fluctuations. IZA Discussion Paper 1765. 2.3.4, 6, 2.5, 2.5.1, 5 
Ngai, L.R., and C. Pissarides. 2006. Trends in hours and economic growth. CEPR Discussion Paper 5440. 1

Pissarides, C.A. 2000. Equilibrium unemployment theory. 2nd ed. Cambridge, MA: MIT Press. 2.1.1, 2.1.1, 2.3.2

Prescott, E.C. 2004. Why do americans work so much more than europeans? Federal Reserve Bank of Minneapolis Quarterly Review 28:2-13. 1

Pries, M.J., and R. Rogerson. 2004. Search frictions and labor market participation. Mimeo ht t p: / / www. gl ue. umd. edu/ mj pries/partic. pdf. 1, 2.1.1

Reiter, Michael. 2002. Recursive computation of heterogeneous agent models. Universitat Pompeu Fabra. B

Reuters. 2004. U.s. jobless rate misses hidden unemployed. Boston.com June 14. htt p: / / www. boston. com/business/articles/2004/06/14/us_jobless_rate_mi sses_hidden_unemp 3

Shimer, R. 2004. Search intensity. Mimeo htt p: / / home, uchicago, edu/ shi mer/wp/intensity, pdf. 1

- 2005a. The cyclical behavior of equilibrium unemployment and vacancies. American Economic Review 95:25-49. 1, 2.3, 2.3.4, 2.6, 3.1, 3.2, 3.2

2005b. Reassessing the ins and outs of unemployment. Presented at EFGS meetings. $1,2.1 .2$

Tripier, F. 2002. Can the labor market search model explain the fluctuations of allocations of time? Economic Modelling 21:131-146. 1

van Soest, A., M. Das, and X. Gong. 2002. A structural labour supply model with flexible preferences. Journal of Econometrics 107:345-374.

Veracierto, M. 2004. On the cycical behavior of employment, unemployment and labor force participation. Federal Reserve Bank of Chicago WP 2002-12. 1, 4.2 


\section{Appendix A Proofs}

Proof of Proposition 1. First we derive the wage curve. For convenience, let us restate the relevant equations here:

$$
\begin{aligned}
(r+\eta+\lambda) V^{n}(h) & =b(h)+\lambda V^{e}(h)+\eta \overline{V^{n}} \quad \text { for } h \leq h^{c} \\
(r+\eta) V^{n}(h) & =h+\eta \overline{V^{n}} \quad \text { for } h>h^{c} \\
h^{c} & =b\left(h^{c}\right)+\lambda\left(V^{e}\left(h^{c}\right)-V^{n}\left(h^{c}\right)\right) . \\
V^{e}(h) & =\frac{w(h)+\chi \overline{V^{n}}}{r+\chi} \\
J(h) & =\frac{z-w(h)}{r+\chi} \\
\alpha J(h) & =(1-\alpha)\left(V^{e}(h)-V^{n}(h)\right) .
\end{aligned}
$$

Equations $(41-46)$ directly correspond to Equations $(7-11)$ in the main text.

First subtract $V^{n}(h)$ from both sides of Equation (44) and plug it into the right hand side of (46). Substitute Equation (45) into the left hand side of (46). Simplify and obtain:

$$
\alpha z=w(h)+(1-\alpha)\left(\chi \overline{V^{n}}-(r+\chi) V^{n}(h)\right) .
$$

Then combine (44) with (41) and eliminate $V^{e}(h)$ :

$$
(r+\chi)(r+\eta+\lambda) V^{n}(h)=(r+\chi) b(h)+\lambda w(h)+(\lambda \chi+\eta r+\eta \chi) \overline{V^{n}} .
$$

Then combine (48) with (47) to eliminate $V^{n}(h)$ and obtain:

$$
w(h)=\frac{r+\eta+\lambda}{r+\eta+\alpha \lambda} \alpha z+\frac{r+\chi}{r+\eta+\alpha \lambda}(1-\alpha) b(h)+\frac{\eta-\chi}{r+\eta+\alpha \lambda}(1-\alpha) r \overline{V^{n}}
$$

which is the wage curve (13). From the last term it is easy to see that imposing EtaChi eliminates all references to the threshold home productivity $h^{c}$. Finally, Assumption ConstB assures that all references to home productivity disappear and the wage curve is equivalent to the standard textbook model.

To derive the job creation condition, insert (10) into (12):

$$
\frac{\phi}{q(\theta)}=\int_{-\infty}^{h^{c}} \frac{z-w(h)}{r+\chi} d F(h) \frac{1}{F\left(h^{c}\right)}
$$

Rearranging (A) we obtain the job creation curve (14).

From the wage curve in (49) we immediately see that the wage is independent of home productivity $h$ under assumption ConstB. This lets us write the job creation condition as in (16).

We have thus shown that assumptions ConstB and EtaChi imply a wage curve and job creation condition that are identical to the standard, constant participation 
model. Equilibrium wages and tightness follow from these two equations, so they must be identical to the standard textbook model, too.

Proof of Proposition 2. In steady state, flows into and out-of each pool have to equal. Since $F\left(h^{c}\right)$ is the probability that an agent participates after receiving a new draw of home productivity, the flow equations for employment $(e)$ and non-participation $(v)$ are given by

$$
\begin{aligned}
\text { Employment } & : u \lambda=\chi e \\
\text { Non-Participation } & :(\chi e+\eta u)\left(1-F\left(h^{c}\right)\right)=\eta F\left(h^{c}\right) v
\end{aligned}
$$

where $u$ is unemployment. Population is normalized to unity, so we have

$$
e+u+v=1
$$

Solve (52) for $v$ and insert it into (51). Then solve (50) for $u$ and insert it into (51). Using the assumption $\eta=\chi$, this gives Equ. (17). Equ. (18) follows from (17) and (50). We obtain Equ. (19) by adding up (17) and (18), since $p=e+u$.

In the following proofs, for compactness of notation, we are going to use $\hat{x}$ (rather than $\mathrm{d} x$ ) to denote the change in the equilibrium value of any variable $x$.

Proof of Proposition 3. For the relevant case $h \leq h^{c}$, workers' surplus satisfies

$$
r \Sigma^{W}(h)=w(h)-b(h)-\lambda \Sigma^{W}(h)+\chi\left(\overline{V^{n}}-V^{e}(h)\right)-\eta\left(\overline{V^{n}}-V^{n}(h)\right)
$$

In the case $\eta=\chi$, this simplifies to

$$
(r+\chi+\lambda) \Sigma^{W}(h)=w(h)-b(h)
$$

Combining (10), (11) and (54) we get

$$
\alpha \frac{z-w(h)}{r+\chi}=(1-\alpha) \frac{w(h)-b(h)}{r+\chi+\lambda}
$$

We can solve (55) for the wage:

$$
w(h)=\frac{\alpha(r+\chi+\lambda) z+(1-\alpha)(r+\chi)(b(h))}{r+\chi+\alpha \lambda}
$$

Using (56) in (10), we get

$$
J(h)=\frac{(1-\alpha)(z-b(h))}{r+\chi+\alpha \lambda}
$$


Inserting (57) into (12), using $\lambda=\theta q(\theta)$, we get

$$
(r+\chi+\alpha \theta q(\theta)) \phi=q(\theta)(1-\alpha)\left[z-\frac{1}{F\left(h^{c}\right)} \int_{-\infty}^{h^{c}} b(h) d F(h)\right]
$$

Substituting the definition (21) and taking total differentials in (58), we get

$$
\alpha \phi\left[q(\theta)+\theta q^{\prime}(\theta)\right] \hat{\theta}=(1-\alpha)\left[q^{\prime}(\theta)\left(z-B\left(h^{c}\right)\right) \hat{\theta}+q(\theta)\left(\hat{z}-\hat{b_{0}}-B^{\prime}\left(h^{c}\right) \hat{h^{c}}\right)\right]
$$

Using $q(\theta)=\theta^{-\vartheta}$ and multiplying both sides in (59) by $\theta^{-\vartheta}$ gives

$$
\alpha \phi(1-\vartheta) \hat{\theta}=(1-\alpha)\left[-\vartheta \frac{z-B\left(h^{c}\right)}{\theta} \hat{\theta}+\left(\hat{z}-\hat{b_{0}}-B^{\prime}\left(h^{c}\right) \hat{h^{c}}\right)\right]
$$

Multiplying (58) by $\alpha /(r+\chi+\alpha \lambda)$, we get

$$
\alpha \phi=\alpha \frac{\lambda}{\theta}(1-\alpha) \frac{z-B\left(h^{c}\right)}{r+\chi+\alpha \lambda}
$$

Using (61) in (60) and rearranging we obtain (20).

Proof of Proposition 4. From (57), using the bargaining condition (11), we get

$$
\Sigma^{W}(h)=\frac{\alpha(z-b(h))}{r+\chi+\alpha \lambda}
$$

Plugging (62) into (8) and using $\lambda=\theta q(\theta)$, we get

$$
h^{c}=\frac{\alpha \theta q(\theta) z+(r+\chi)\left(b\left(h^{c}\right)\right)}{r+\chi+\alpha \theta q(\theta)}
$$

Multiplying (63) by $r+\chi+\alpha \theta q(\theta)$ and taking total differentials, we get

$$
\begin{aligned}
\alpha\left[q(\theta)+\theta q^{\prime}(\theta)\right] h^{c} \hat{\theta} & +(r+\chi+\alpha \theta q(\theta)) \hat{h^{c}} \\
& =\alpha\left[q(\theta)+\theta q^{\prime}(\theta)\right] z \hat{\theta}+\alpha \theta q(\theta) \hat{z}+(r+\chi)\left(\hat{b_{0}}+b^{\prime}\left(h^{c}\right) \hat{h^{c}}\right)
\end{aligned}
$$

This can be rearranged to give

$$
\begin{aligned}
\hat{h^{c}} & =\frac{\alpha\left[q(\theta)+\theta q^{\prime}(\theta)\right]\left(z-h^{c}\right) \hat{\theta}+\alpha \theta q(\theta) \hat{z}+(r+\chi)\left(\hat{b_{0}}+b^{\prime}\left(h^{c}\right) \hat{h^{c}}\right)}{r+\chi+\alpha \theta q(\theta)} \\
& =\frac{\alpha \lambda \hat{z}+(r+\chi)\left(\hat{b_{0}}+b^{\prime}\left(h^{c}\right) \hat{h^{c}}\right)}{r+\chi+\alpha \lambda}+\frac{\alpha(1-\vartheta) \lambda\left(z-h^{c}\right)}{r+\chi+\alpha \lambda} \frac{\hat{\theta}}{\theta}
\end{aligned}
$$

Plugging (20) and (63) into the last expression in (65), we get

$$
\begin{aligned}
\hat{h^{c}}= & \frac{\alpha \lambda \hat{z}+(r+\chi)\left(\hat{b_{0}}+b^{\prime}\left(h^{c}\right) \hat{h^{c}}\right)}{r+\chi+\alpha \lambda} \\
& +\Phi \frac{\alpha(1-\vartheta) \lambda}{(r+\chi+\alpha \lambda)} \frac{(r+\chi)}{(\vartheta(r+\chi)+\alpha \lambda)}\left(\hat{z}-\hat{b_{0}}-B^{\prime}\left(h^{c}\right) \hat{h^{c}}\right)
\end{aligned}
$$


where

$$
\Phi=\frac{\left(z-b\left(h^{c}\right)\right)}{z-B\left(h^{c}\right)}
$$

$\Phi$ is the ratio of the instantaneous match surplus of the marginal participant $(z-$ $\left.b\left(h^{c}\right)\right)$ and the average instantaneous match surplus $\left(z-B\left(h^{c}\right)\right)$. Since the marginal participant has the higher home productivity, we have

$$
0 \leq \Phi \leq 1
$$

Note that $\Phi=1$ under Assumption ConstB.

We can write (66) as

$$
\kappa_{h} \hat{h^{c}}=\kappa_{z} \hat{z}+\kappa_{b} \hat{b_{0}}
$$

where

$$
\begin{aligned}
& \kappa_{h}=1-\frac{(r+\chi)}{r+\chi+\alpha \lambda} b^{\prime}\left(h^{c}\right)+\Phi \frac{\alpha(1-\vartheta) \lambda}{(r+\chi+\alpha \lambda)} \frac{(r+\chi)}{(\vartheta(r+\chi)+\alpha \lambda)} B^{\prime}\left(h^{c}\right) \\
& \kappa_{z}=\frac{\alpha \lambda}{r+\chi+\alpha \lambda}+\Phi \frac{\alpha(1-\vartheta) \lambda}{(r+\chi+\alpha \lambda)} \frac{(r+\chi)}{(\vartheta(r+\chi)+\alpha \lambda)} \\
& \kappa_{b}=\frac{r+\chi}{r+\chi+\alpha \lambda}-\Phi \frac{\alpha(1-\vartheta) \lambda}{(r+\chi+\alpha \lambda)} \frac{(r+\chi)}{(\vartheta(r+\chi)+\alpha \lambda)}
\end{aligned}
$$

Using the inequalities (1), (68) and $0 \leq B^{\prime}\left(h^{c}\right) \leq 1$, we can derive

$$
\begin{aligned}
\frac{\alpha \lambda}{r+\chi+\alpha \lambda} & \leq \kappa_{h} \leq \frac{(r+\chi)(\vartheta(r+\chi)+\alpha \lambda)+\alpha \lambda(r+\chi+\alpha \lambda)}{(r+\chi+\alpha \lambda)(\vartheta(r+\chi)+\alpha \lambda)} \\
\frac{\alpha \lambda}{r+\chi+\alpha \lambda} & \leq \kappa_{z} \leq \frac{\alpha \lambda}{\vartheta(r+\chi)+\alpha \lambda} \\
\frac{\vartheta(r+\chi)}{\vartheta(r+\chi)+\alpha \lambda} & \leq \kappa_{b} \leq \frac{r+\chi}{r+\chi+\alpha \lambda}
\end{aligned}
$$

Equations (22) and (24) follow from (69) and (70) using $B^{\prime}\left(h^{c}\right)=b^{\prime}\left(h^{c}\right)=0$ and $\Phi=1$. The inequalities (23) and (25) follow from (69) and (71). For example, the first inequality in (23) is obtained by combining the first inequality in (71b) with the second inequality in (71a).

\section{Appendix B The differentiated-wage model}

The equations of the DW-model are very similar to Equ. (28)-(33) of the EW-model. The main difference is that the wage depends on home productivity, and that most variables now depend on the cross-sectional distribution of home productivity, as was explained in Section 2.4. We therefore write $V_{i, \Omega}^{n}(h)$ rather than $V_{i}^{n}(h)$, etc. The subscript $i$ still refers to the realization of aggregate productivity, while $\Omega$ refers to 
all other state variables. In theory, $\Omega$ contains the whole cross-sectional distribtuion of home productivity. In the numerical approximation, this has to be replaced by a finite-dimensional vector characterizing this distribution. Furthermore, the equations for $V_{i, \Omega}^{n}(h)$, etc., include terms that capture the effect of the change in $\Omega$ on $V_{i, \Omega}^{n}(h)$.

The model then consists of Equ. (27) plus the following equations:

Participation decision:

$$
\begin{aligned}
r V_{i, \Omega}^{n}(h)=\eta\left(\overline{V_{i, \Omega}^{n}}-V_{i, \Omega}^{n}(h)\right)+\sum_{j} p_{i, j} V_{j, \Omega}^{n}(h) & +\frac{d V_{i, \Omega}^{n}(h)}{d \Omega} \frac{d \Omega}{d t} \\
& +\max \left\{b(h)+\lambda_{i, \Omega}\left(V_{i, \Omega}^{e}(h)-V_{i, \Omega}^{n}(h)\right), h\right\}
\end{aligned}
$$

The threshold level of home productivity:

$$
h_{i, \Omega}^{c}=b\left(h_{i, \Omega}^{c}\right)+\lambda_{i, \Omega}\left(V_{i, \Omega}^{e}(h)-V_{i, \Omega}^{n}\left(h_{i, \Omega}^{c}\right)\right)
$$

Value of the employed:

$$
r V_{i, \Omega}^{e}(h)=w_{i, \Omega}(h)+\chi\left(\overline{V_{i, \Omega}^{n}}-V_{i, \Omega}^{e}(h)\right)+\sum_{j} p_{i, j} V_{j, \Omega}^{e}(h)+\frac{d V_{i, \Omega}^{e}(h)}{d \Omega} \frac{d \Omega}{d t}
$$

Value of a filled job:

$$
(r+\chi) J_{i, \Omega}(h)=z_{i}-w_{i, \Omega}(h)+\sum_{j} p_{i, j} J_{j, \Omega}(h)+\frac{d J_{i, \Omega}(h)}{d \Omega} \frac{d \Omega}{d t}
$$

Bargaining condition:

$$
\alpha J_{i, \Omega}(h)=(1-\alpha)\left(V_{i, \Omega}^{e}(h)-V_{i, \Omega}^{n}(h)\right)
$$

\section{Numerical solution}

As mentioned above, the vector of state variables includes the cross-sectional distribution of home productivity, which is an infinite-dimensional object. To compute an approximate solution, we use a state-aggregation approach similar to Krusell and Smith (1998), where value functions are written as functions of a finite number of statistics (moments) of this distribution. The algorithm we use is described in Reiter (2002). The statistics we use are the fraction of non-employed households, and the average home productivity of the non-employed. 


\section{Appendix C Data Sources}

All labor market series originate from the BLS website and are seasonally adjusted. Age is 16 years and older. The participation rate series (Id LNS11300000); the unemployment rate series (Id LNS14000000); the employment population rate series (Id LNS12300000).

The remaining series are all available via the FRED database. All are seasonally adjusted. Real GDP $(2000=100)$ can be obtained via ht t p: / / research. st I ouisfed.org/fred2/series/GDPC1/ 106.

Vacancies are measured by the help-wanted index ht t p: / / research. st I oui sf ed. or g/ fred2/ seri es / HEL PWANT / 10 (1987=100); the wage series is average hourly earnings, total private industries ht t p: / / research. st louisfed.org/fred2/series/ahet pi / 10.

It is deflated using the private consumption expenditure price index ht t p: / / research.st louisfed. org/fred2/ series/ pcepi / 21 (Base 2000).

Labor productivity is measured as output per worker and was constructed by Robert Shimer. For additional details, please see his webpage, ht t p: / / home. uchicago, edu/ shi mer/data / mmm/.

When available, all series were downloaded at a monthly frequency and converted to quarterly frequency by averaging. GDP and output/worker are at quarterly frequency.

\section{Appendix D Tables}




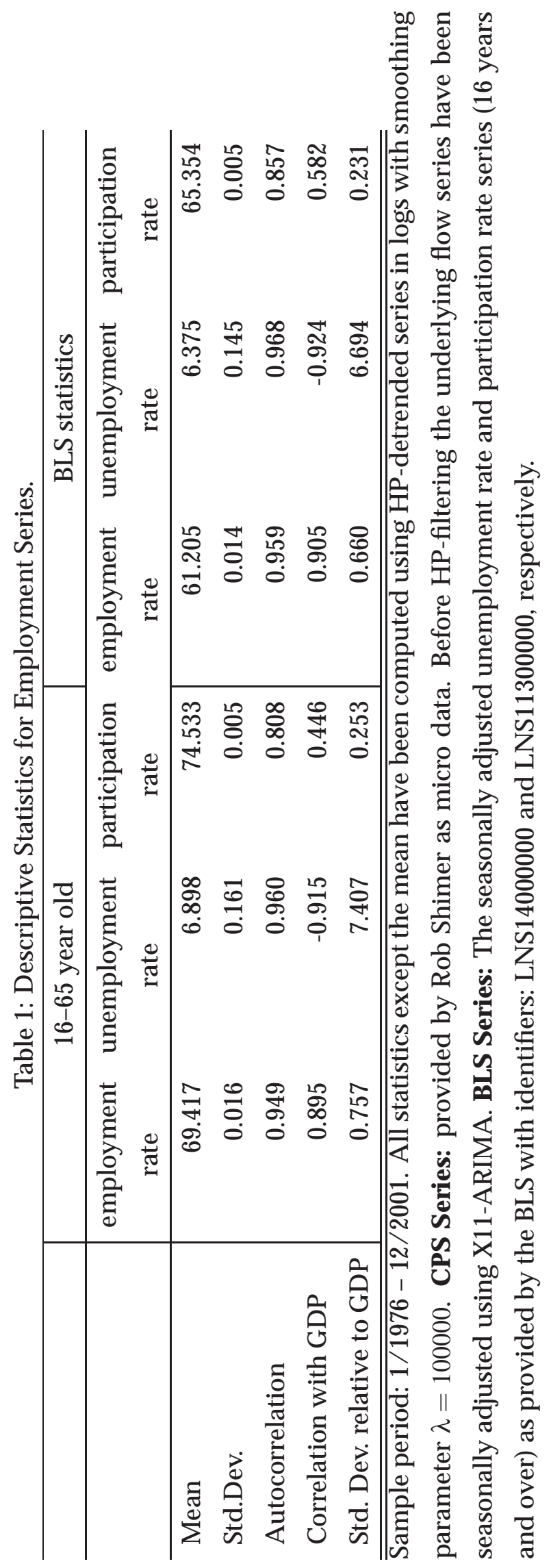


Table 2: Baseline Calibration (flexible and rigid wages)

\begin{tabular}{lcc}
\hline Parameters & Symbol & Value \\
Interest rate & $r$ & 0.012 \\
AR(1) labor productivity & $\rho_{z}$ & 0.95 \\
Stand.dev. labor productivity & $\sigma_{z}$ & 0.0039 \\
Scaling Parameter of Matching Function & $\mu$ & 1 \\
Elasticity of Matching Function & $\vartheta$ & 0.5 \\
Mean bargaining parameter & $\alpha$ & 0.5 \\
Variation bargaining parameter (only rigid wages) & $\Delta_{\alpha}$ & 5.180 \\
Exogenous Job Separation Prob. & $\chi$ & 0.099 \\
Redraw Probability of home production & $\eta$ & 0.099 \\
\hline Flow utility of unemployment & $b$ & 0.6125 \\
Density of home production & $f(h)=\frac{1}{2 \sigma}$ & 0.424 \\
\hline Median home production & $\bar{h}$ & 0.360 \\
Vacancy posting costs & $\phi$ & 1.398 \\
Matched facts & & \\
\hline Unemployment Rate & & 0.0638 \\
Participation Rate & & \\
Long-run elasticity of unemployment & & 1.3 \\
with respect to benefits & &
\end{tabular}




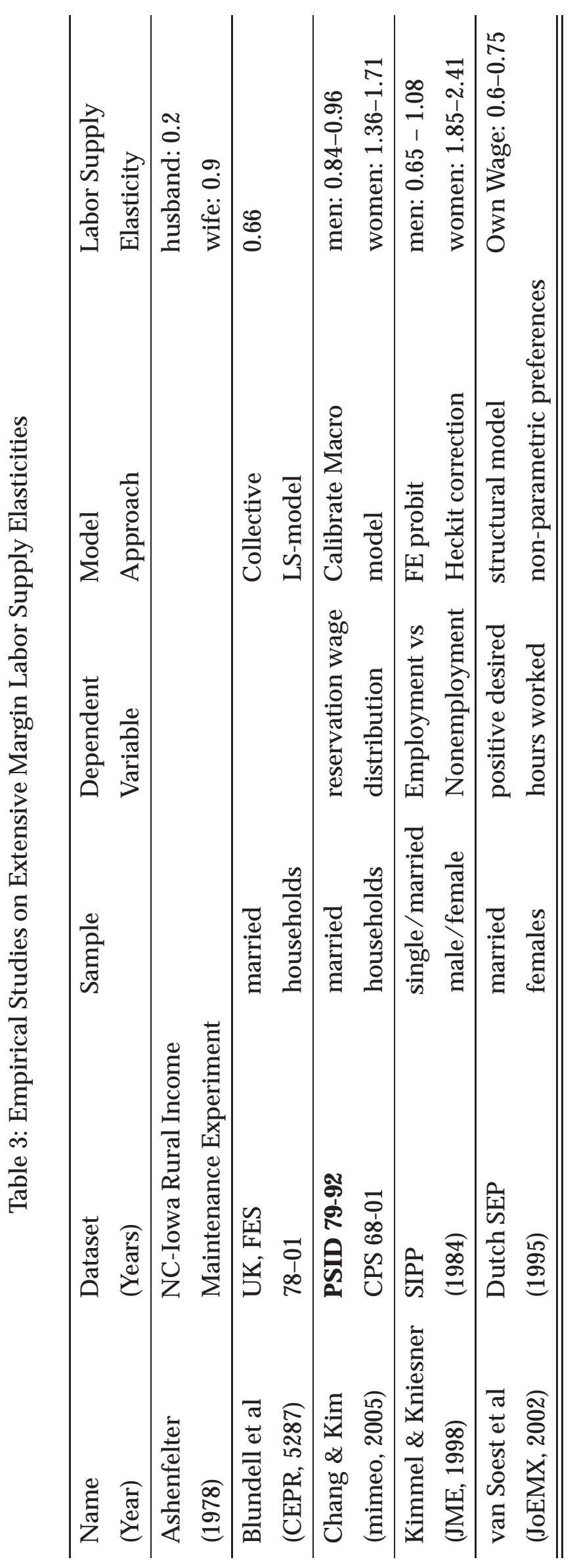


Table 4: Descriptive Statistics for Data.

\begin{tabular}{lccccc}
\hline & Mean & $\sigma_{\mathbf{x}}$ & $\frac{\sigma_{\mathbf{x}}}{\sigma_{\mathrm{GDP}}}$ & $\rho_{-\mathbf{1}}$ & $\rho_{\mathbf{x}, \mathbf{G D P}}^{\mathbf{q}}$ \\
\hline Participation rate & 65.354 & 0.50 & 0.231 & 0.877 & 0.549 \\
Employment rate & 61.205 & 1.43 & 0.660 & 0.955 & 0.896 \\
Unemployment & 4.150 & 14.26 & 6.566 & 0.947 & -0.918 \\
Vacancies & 81.481 & 18.63 & 8.581 & 0.952 & 0.821 \\
Real wage & 0.128 & 1.51 & 0.694 & 0.972 & 0.109 \\
Real GDP & 6888.580 & 2.17 & 1.000 & 0.932 & 1.000 \\
\hline \hline
\end{tabular}

Data sample period: 1/1976 - 12/2001. All statistics except the mean have been computed using HP-detrended series in logs with smoothing parameter $\lambda=100000$. Column $\left(\sigma_{x}\right)$ reports standard deviations in percent. Column $\left(\frac{\sigma_{x}}{\sigma_{G D P}}\right)$ reports the standard deviation of each series relative to the standard deviation of GDP. Column $\left(\rho_{-1}\right)$ reports autocorrelations. Columns $\left(\rho_{x, G D P}\right)$ report correlations with GDP at quarterly, monthly, and annual frequency, respectively. 
Table 5: Descriptive Statistics for the Flexible Wage Model.

\begin{tabular}{|c|c|c|c|c|c|c|c|}
\hline & Mean & $\sigma_{\mathbf{x}}$ & $\frac{\sigma_{\mathrm{x}}}{\sigma_{\mathrm{GDP}}}$ & $\rho_{-1}$ & $\rho_{\mathrm{x}, \mathrm{GDP}}^{\mathbf{q}}$ & $\rho_{\mathbf{x}, \mathbf{G D P}}^{\mathbf{m}}$ & $\rho_{\mathbf{x}, \text { GDP }}^{\mathbf{a}}$ \\
\hline \multicolumn{8}{|c|}{ Results with Constant Participation. } \\
\hline Participation rate & 65.318 & 0.000 & 0.000 & 0.953 & 0.846 & 0.816 & 0.877 \\
\hline Employment rate & 61.145 & 0.085 & 0.066 & 0.924 & 0.965 & 0.935 & 0.988 \\
\hline Unemployment & 4.173 & 1.239 & 0.968 & 0.924 & -0.965 & -0.935 & -0.988 \\
\hline Vacancies & 0.977 & 1.579 & 1.241 & 0.802 & 0.972 & 0.957 & 0.989 \\
\hline Real wage & 97.515 & 1.174 & 0.919 & 0.884 & 1.000 & 1.000 & 1.000 \\
\hline Real GDP & 61.159 & 1.279 & 1.000 & 0.889 & 1.000 & 1.000 & 1.000 \\
\hline \multicolumn{8}{|c|}{ Results with Endogenous Participation, EW. } \\
\hline Participation rate & 65.365 & 0.358 & 0.227 & 0.953 & 0.911 & 0.887 & 0.932 \\
\hline Employment rate & 61.188 & 0.428 & 0.271 & 0.959 & 0.896 & 0.855 & 0.929 \\
\hline Unemployment & 4.177 & 1.084 & 0.703 & 0.611 & -0.498 & -0.286 & -0.748 \\
\hline Vacancies & 0.979 & 2.504 & 1.618 & 0.736 & 0.875 & 0.839 & 0.922 \\
\hline Real wage & 97.515 & 1.174 & 0.751 & 0.884 & 0.988 & 0.987 & 0.990 \\
\hline Real GDP & 61.210 & 1.569 & 1.000 & 0.913 & 000 & 1.000 & 1.000 \\
\hline \multicolumn{8}{|c|}{ Results with Endogenous Participation, DW, $b(h)=b_{0}$. } \\
\hline Participation rate & 65.353 & 0.365 & 0.227 & 0.953 & 0.910 & 0.886 & 0.934 \\
\hline Employment rate & 61.218 & 0.447 & 0.279 & 0.958 & 0.904 & 0.866 & 0.936 \\
\hline Unemployment & 4.135 & 1.159 & 0.736 & 0.692 & -0.636 & -0.436 & -0.845 \\
\hline Vacancies & 0.989 & 2.721 & 1.733 & 0.749 & 0.888 & 0.856 & 0.933 \\
\hline Real wage & 97.489 & 1.164 & 0.735 & 0.884 & 0.988 & 0.987 & 0.990 \\
\hline Real GDP & 61.239 & 1.591 & 1.000 & 0.913 & 1.000 & 1.000 & 1.000 \\
\hline \multicolumn{8}{|c|}{ Results with Endogenous Participation, DW, $b(h)=h-0.2$. } \\
\hline Participation rate & 65.308 & 0.383 & 0.248 & 0.952 & 0.914 & 0.887 & 0.934 \\
\hline Employment rate & 61.153 & 0.407 & 0.263 & 0.965 & 0.848 & 0.789 & 0.892 \\
\hline Unemployment & 4.155 & 1.085 & 0.724 & 0.591 & 0.359 & 0.424 & 0.280 \\
\hline Vacancies & 0.981 & 1.379 & 0.907 & 0.742 & 0.870 & 0.812 & 0.935 \\
\hline Real wage & 92.658 & 1.213 & 0.796 & 0.888 & 0.989 & 0.988 & 0.990 \\
\hline Real GDP & 61.174 & 1.531 & 1.000 & 0.913 & 1.000 & 1.000 & 1.000 \\
\hline
\end{tabular}

Averages over 1000 simulations of length 104 quarters. All statistics except the mean have been computed using HP-detrended series in logs with smoothing parameter $\lambda=100000$. Column $\left(\sigma_{x}\right)$ reports standard deviations in percent. Column $\left(\frac{\sigma_{x}}{\sigma_{G D P}}\right)$ reports the standard deviation of each series relative to the standard deviation of GDP. Column $\left(\rho_{-1}\right)$ reports autocorrelations. Columns $\left(\rho_{x, G D P}\right)$ report correlations with GDP at quarterly, monthly, and annual frequency, respectively. 
Table 6: Descriptive Statistics for the Rigid Wage Model.

\begin{tabular}{lccccc|cc}
\hline & Mean & $\sigma_{\mathbf{x}}$ & $\frac{\sigma_{\mathbf{x}}}{\sigma_{\mathbf{G D P} P}}$ & $\rho_{-\mathbf{1}}$ & $\rho_{\mathbf{x}, \mathbf{G D P}}^{\mathbf{q}}$ & $\rho_{\mathbf{x}, \mathbf{G D P}}^{\mathbf{m}}$ & $\rho_{\mathbf{x}, \mathbf{G D P}}^{\mathbf{a}}$ \\
\hline \multicolumn{7}{l}{ Results with Endogenous Participation, EW. } \\
\hline Participation rate & 65.325 & 0.360 & 0.150 & 0.952 & 0.915 & 0.897 & 0.933 \\
Employment rate & 61.063 & 1.227 & 0.513 & 0.936 & 0.981 & 0.970 & 0.990 \\
Unemployment & 4.262 & 12.393 & 5.234 & 0.920 & -0.981 & -0.963 & -0.993 \\
Vacancies & 1.011 & 17.472 & 7.420 & 0.792 & 0.914 & 0.873 & 0.957 \\
Real wage & 97.454 & 0.706 & 0.299 & 0.851 & 0.910 & 0.872 & 0.947 \\
Real GDP & 61.101 & 2.380 & 1.000 & 0.922 & 1.000 & 1.000 & 1.000 \\
\hline Results with Endogenous Participation, DW, $b(h)=h-0.2$. & & \\
\hline Participation rate & 65.302 & 0.373 & 0.160 & 0.951 & 0.912 & 0.892 & 0.929 \\
Employment rate & 61.089 & 1.148 & 0.496 & 0.936 & 0.980 & 0.968 & 0.988 \\
Unemployment & 4.213 & 11.174 & 4.868 & 0.918 & -0.982 & -0.964 & -0.994 \\
Vacancies & 1.011 & 15.857 & 6.942 & 0.793 & 0.920 & 0.879 & 0.962 \\
Real wage & 92.527 & 0.700 & 0.323 & 0.593 & -0.438 & -0.394 & -0.527 \\
Real GDP & 61.125 & 2.304 & 1.000 & 0.919 & 1.000 & 1.000 & 1.000 \\
\hline
\end{tabular}

Averages over 1000 simulations of length 104 quarters. All statistics except the mean have been computed using HP-detrended series in logs with smoothing parameter $\lambda=100000$. Column $\left(\sigma_{x}\right)$ reports standard deviations in percent. Column $\left(\frac{\sigma_{x}}{\sigma_{G D P}}\right)$ reports the standard deviation of each series relative to the standard deviation of GDP. Column $\left(\rho_{-1}\right)$ reports autocorrelations. Columns $\left(\rho_{x, G D P}\right)$ report correlations with GDP at quarterly, monthly, and annual frequency, respectively. 
Table 7: Descriptive Statistics for the Small-Surplus Calibrations.

\begin{tabular}{|c|c|c|c|c|c|c|c|}
\hline & Mean & $\sigma_{\mathbf{x}}$ & $\frac{\sigma_{\mathrm{X}}}{\sigma_{\mathrm{GDP}}}$ & $\rho_{-1}$ & $\rho_{\mathrm{x}, \mathrm{GDP}}^{\mathbf{q}}$ & $\rho_{\mathbf{x}, \mathbf{G D P}}^{\mathbf{m}}$ & $\rho_{\mathrm{x}, \mathrm{GDP}}^{\mathrm{a}}$ \\
\hline \multicolumn{8}{|c|}{ Results with Endogenous Participation, EW. } \\
\hline Participation rate & 65.410 & 0.209 & 0.098 & 0.950 & 0.885 & 0.862 & 0.900 \\
\hline Employment rate & 60.868 & 1.007 & 0.471 & 0.929 & 0.976 & 0.962 & 0.987 \\
\hline Unemployment & 4.542 & 10.376 & 4.883 & 0.919 & -0.980 & -0.963 & -0.993 \\
\hline Vacancies & 0.927 & 14.802 & 6.988 & 0.780 & 0.914 & 0.875 & 0.956 \\
\hline Real wage & 97.239 & 0.694 & 0.332 & 0.877 & 0.979 & 0.970 & 0.986 \\
\hline Real GDP & 60.899 & 2.120 & 1.000 & 0.914 & 1.000 & 1.000 & 1.000 \\
\hline \multicolumn{8}{|c|}{ Results with Endogenous Participation, DW, $b(h)=0.4+0.5 h$. } \\
\hline Participation rate & 65.833 & 5.422 & 0.836 & 0.952 & 0.994 & 0.987 & 0.998 \\
\hline Employment rate & 61.655 & 5.505 & 0.848 & 0.963 & 0.992 & 0.988 & 0.995 \\
\hline Unemployment & 4.178 & 12.497 & 2.012 & 0.576 & 0.334 & 0.282 & 0.423 \\
\hline Vacancies & 0.997 & 16.581 & 2.644 & 0.687 & 0.581 & 0.494 & 0.690 \\
\hline Real wage & 99.126 & 1.115 & 0.176 & 0.885 & 0.844 & 0.802 & 0.879 \\
\hline Real GDP & 61.787 & 6.473 & 1.000 & 0.959 & 1.000 & 1.000 & 1.000 \\
\hline
\end{tabular}

Averages over 1000 simulations of length 104 quarters. All statistics except the mean have been computed using HP-detrended series in logs with smoothing parameter $\lambda=100000$. Column $\left(\sigma_{x}\right)$ reports standard deviations in percent. Column $\left(\frac{\sigma_{x}}{\sigma_{G D P}}\right)$ reports the standard deviation of each series relative to the standard deviation of GDP. Column $\left(\rho_{-1}\right)$ reports autocorrelations. Columns $\left(\rho_{x, G D P}\right)$ report correlations with GDP at quarterly, monthly, and annual frequency, respectively.

Table 8: Monthly Flows in Data and Benchmark Model.

\begin{tabular}{rrrr|lrrr}
\hline & \multicolumn{3}{c|}{ Data } & \multicolumn{4}{c}{ Benchmark Model } \\
\hline & Unempl. & Home & Empl. & & Unempl. & Home & Empl. \\
$\mathrm{U}$ & 0.663 & 0.141 & 0.225 & $\mathrm{U}$ & 0.613 & 0.008 & 0.379 \\
$\mathrm{H}$ & 0.022 & 0.951 & 0.027 & $\mathrm{H}$ & 0.019 & 0.976 & 0.005 \\
$\mathrm{E}$ & 0.012 & 0.018 & 0.970 & $\mathrm{E}$ & 0.019 & 0.008 & 0.973 \\
\hline \hline
\end{tabular}

Averages over 1000 simulations of length 104 quarters. 


\section{Appendix E Graphs}

Figure 1: Correlations and Variances for rigid and flexible model.
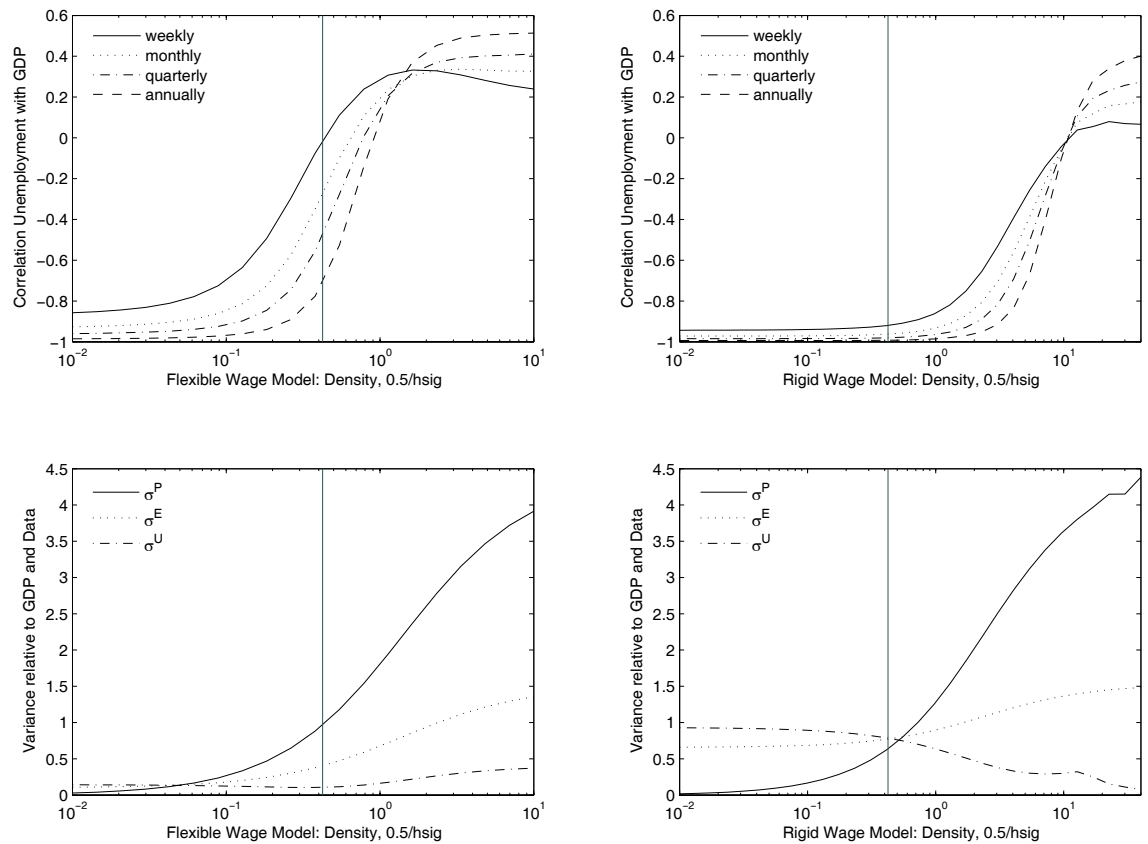

The benchmark calibration is indicated by the horizontal lines. 
Figure 2: Sensitivity to parameter changes
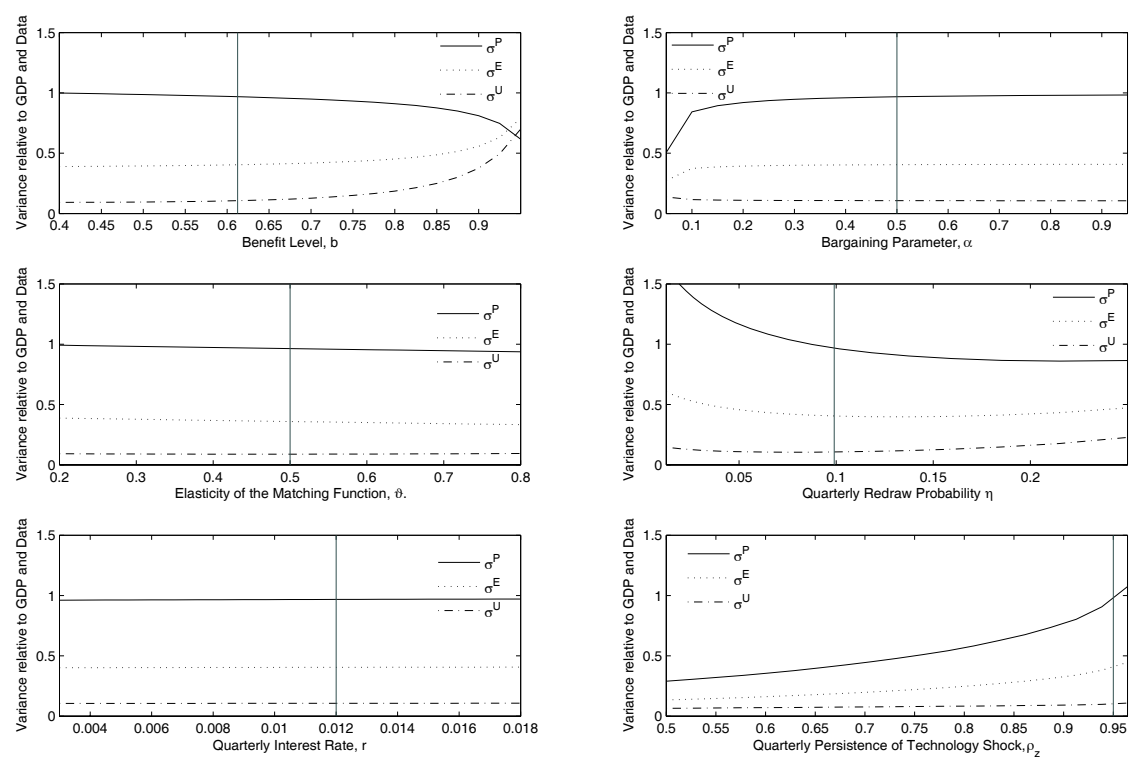

The benchmark calibration is indicated by the horizontal lines. We see that the parameters $\vartheta$ and $r$ have no significant effect on any of the variances. The other parameters do have some effect, in particular if one considers extreme values. A higher benefit level $b$ reduces the match surplus and increases the variability of unemployment, as we have discussed after Proposition 4. Lowering workers' bargaining share $\alpha$ reduces the responsiveness of the participation threshold (Equ. (22)) and thereby the variability of participation. A lower redraw probability $\eta$ increases the variability of all labor market aggregates, which seems to work in favor of the model. Nevertheless, we have argued in Section 2.2 that this is probably artificial, so we do not follow it up here. Finally, a higher persistance of the technology shock, $\rho_{z}$, increases the variance of participation. A worker at the participation threshold is lured into the labor market by an increase in productivity only if the increase is sufficiently persistent so as to make the investment of being unemployed worthwhile. 
Figure 3: Impulse Response Functions
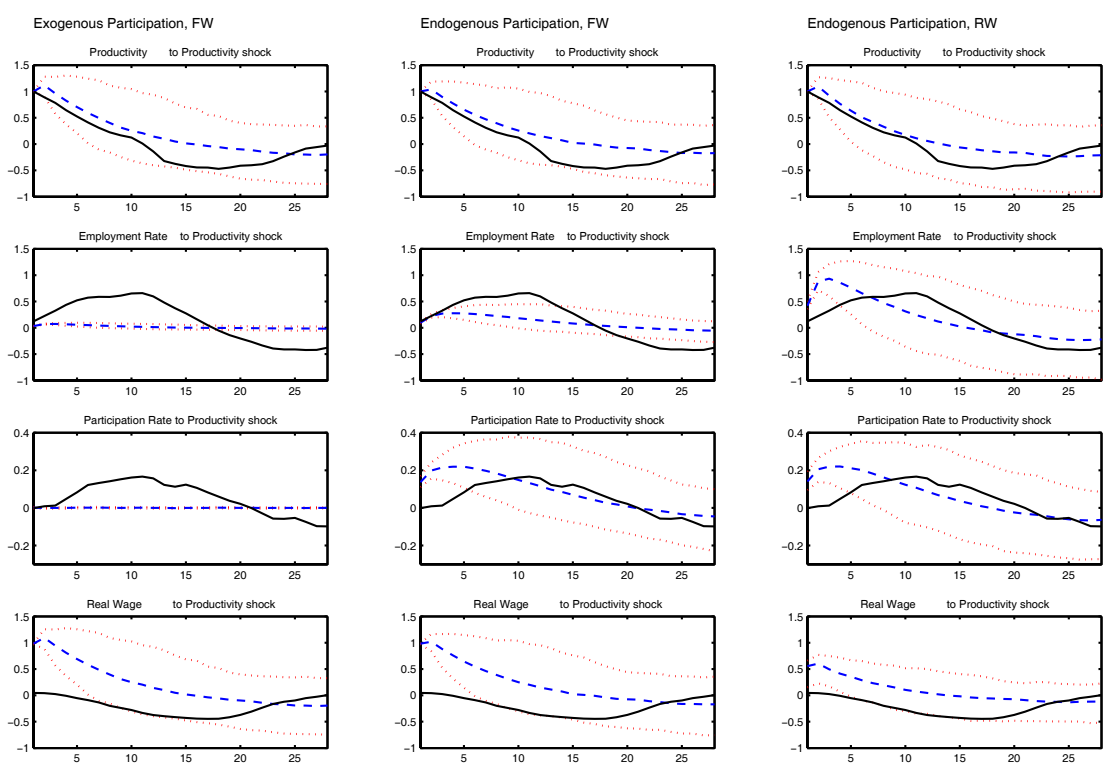

Models are in columns. The first column pertains to the standard model with constant participation. In column 2 we find the responses of the flexible wage (EW) model with endogenous participation, and column 3 shows responses for the rigid wage model with a participation decision.

The bold black line is the local projection impulse response function (Jorda, 2005) estimated for the data in response to a unit shock in productivity. The data has been orthogonalized using the Cholesky decomposition, the ordering is as presented in the figure, i.e. labor productivity, employment rate, participation rate, real wage. The central dotted line represents the average response of the simulated data. The two outer dotted lines are such that 950 of 1000 computed responses lie within them. 